\title{
Cloud susceptibility and the first aerosol indirect forcing: Sensitivity to black carbon and aerosol concentrations
}

\author{
Catherine C. Chuang, ${ }^{1}$ Joyce E. Penner, ${ }^{2}$ Joseph M. Prospero, ${ }^{3}$ Keith E. Grant, ${ }^{1}$ \\ Gregory H. Rau, ${ }^{4}$ and Kazuaki Kawamoto ${ }^{5,6}$ \\ Received 4 December 2000; revised 8 January 2002; accepted 18 January 2002; published 7 November 2002.
}

[1] Present-day global anthropogenic emissions contribute more than half of the mass in submicron particles primarily due to sulfate and carbonaceous aerosol components derived from fossil fuel combustion and biomass burning. These anthropogenic aerosols increase cloud drop number concentration and cloud albedo. Here, we use an improved version of the fully coupled climate/chemistry models to investigate cloud susceptibility and the first indirect effect of anthropogenic aerosols (the Twomey effect). We examine the correspondence between the model simulation of cloud susceptibility and that inferred from satellite measurements to test whether our simulated aerosol concentrations and aerosol/cloud interactions give a faithful representation of these features. This comparison provides an overall measure of the adequacy of cloud cover and drop concentrations. We also address the impact of black carbon absorption in clouds on the first indirect forcing and examine the sensitivity of the forcing to different representations of natural aerosols. We find that including this absorption does not change the global forcing by more than $0.07 \mathrm{~W} \mathrm{~m}^{-2}$, but that locally it could decrease the forcing by as much as $0.7 \mathrm{~W}$ $\mathrm{m}^{-2}$ in regions where black carbon emissions are pronounced. Because of the nonlinear relationship between cloud drop number and aerosol number concentrations, the total forcing does not equal the sum of the forcing from each individual source. Our estimated total first indirect forcing is $-1.85 \mathrm{~W} \mathrm{~m}^{-2}$, with $-0.30 \mathrm{~W} \mathrm{~m}^{-2}$ associated with anthropogenic sulfate, $-1.16 \mathrm{~W} \mathrm{~m}^{-2}$ associated with carbonaceous aerosols from biomass burning, and $-0.52 \mathrm{~W} \mathrm{~m}^{-2}$ associated with carbonaceous aerosols from fossil fuel combustion. Estimates of forcing by sulfate and total carbonaceous aerosols increase to -0.31 and $-1.67 \mathrm{~W} \mathrm{~m}^{-2}$, respectively, if natural emissions of organic aerosols are only 8.4 $\mathrm{Tg} \mathrm{yr}^{-1}$, but decrease to -0.26 and $-1.27 \mathrm{~W} \mathrm{~m}^{-2}$ if they are as large as $42 \mathrm{Tg} \mathrm{yr}^{-1}$. Even larger estimates of forcing are derived if dust and sea-salt emissions are not included. The effect of aerosol abundance on cloud life cycle may be important but is not treated in this study. INDEX TERMS: 0305 Atmospheric Composition and Structure: Aerosols and particles (0345, 4801); 0320 Atmospheric Composition and Structure: Cloud physics and chemistry; 1610 Global Change: Atmosphere $(0315,0325)$

Citation: Chuang, C. C., J. E. Penner, J. M. Prospero, K. E. Grant, G. H. Rau, and K. Kawamoto, Cloud susceptibility and the first aerosol indirect forcing: Sensitivity to black carbon and aerosol concentrations, J. Geophys. Res., 107(D21), 4564, doi:10.1029/2000JD000215, 2002.

\footnotetext{
${ }^{1}$ Atmospheric Science Division, Lawrence Livermore National Laboratory, Livermore, California, USA.

${ }^{2}$ Department of Atmospheric, Oceanic, and Space Sciences, University of Michigan, Ann Arbor, Michigan, USA.

${ }^{3}$ Cooperative Institute for Marine and Atmospheric Studies, University of Miami, Miami, Florida, USA.

${ }^{4}$ Institute of Marine Sciences, University of California, Santa Cruz, California, USA.

${ }^{5}$ Virginia Polytechnic Institute and State University, Blacksburg, Virginia, USA.

${ }^{6}$ Atmospheric Sciences Division, NASA Langley Research Center, Hampton, Virginia, USA.
}

Copyright 2002 by the American Geophysical Union. 0148-0227/02/2000JD000215

\section{Introduction}

[2] One of the largest uncertainties in model simulations of climate change over the industrial period is the impact of anthropogenic aerosols on the Earth's radiation budget. In particular, the assessment of the effect of aerosol/cloud interactions on climate is highly uncertain [Intergovernmental Panel on Climae Change (IPCC), 1996]. This uncertainty arises from a limited capability to precisely link precursor gases to aerosol formation and size distribution, to quantitatively describe the existing levels of global aerosol loading, to accurately predict the nonlinear processes associated with cloud drop nucleation, and to simulate the interactions of cloud dynamics and microphysics.

[3] It has been estimated that the present-day global anthropogenic emissions contribute more than half of the 
mass in submicron particles primarily due to sulfate and carbonaceous aerosol components derived from fossil fuel combustion and biomass burning [Andreae, 1995; Penner, 1995]. These anthropogenic aerosols serve as cloud condensation nuclei $(\mathrm{CCN})$ and enhance the reflectivity of lowlevel water clouds, leading to a cooling effect on climate (the Twomey effect or first indirect effect). In contrast to the aerosol direct effect which is more significant over land, the Twomey effect is much more pronounced over the oceans where clouds are relatively optically thin and likely to be of higher susceptibility [Chuang et al., 1997]. The estimate of sulfate forcing associated with this mechanism ranges from -0.5 to $-1.6 \mathrm{~W} \mathrm{~m}^{-2}$ [Jones et al., 1994; Boucher and Lohmann, 1995; Jones and Slingo, 1996; Chuang et al., 1997; Feichter et al., 1997; Lohmann and Feichter, 1997]. Increases of anthropogenic aerosols may also alter the development of precipitation by affecting the initial size distribution of cloud drops and thereby influencing the cloud lifetime and liquid water content (the second indirect effect). The increased cloud longevity could give rise to a higher cloud cover fraction and liquid water content and further enhance the cooling [Lohmann and Feichter, 1997; Rotstayn, 1999; Lohmann et al., 2000]. Using an empirical relationship between sulfate mass and cloud drop number concentration, the estimate of total indirect forcing by sulfate aerosols amounts to $-2.1 \mathrm{~W} \mathrm{~m}^{-2}$ as obtained by Rotstayn [1999] and ranges from -1.4 to $-4.8 \mathrm{~W} \mathrm{~m}^{-2}$ as obtained by Lohmann and Feichter [1997]. Employing a mechanistic parameterization of cloud drop nucleation developed by Chuang and Penner [1995], Lohmann et al. [2000] obtained the total indirect forcing by sulfate and carbonaceous aerosols between -1.1 to $-1.5 \mathrm{~W} \mathrm{~m}^{-2}$. The wide range of indirect forcing reported by Lohmann and Feichter [1997] shows that the magnitude of second indirect effect is highly sensitive to the treatments of cloud drop autoconversion rate and cloud cover parameterization that are applied within climate models to calculate the second indirect forcing. However, our focus in this study is on the equally important issue of the first indirect effect. Unlike the calculation of the second indirect effect, for calculations of the first indirect effect, it may be assumed that the liquid water content and cloud amount remain fixed. Thus, the forcing can be calculated exactly, keeping these quantities fixed and calling the radiation subroutines of the model twice [Rotstayn and Penner, 2001]. This is the procedure followed here. Here, we examine and quantify the first indirect effect and its sensitivity to natural emissions and the role of absorption by black carbon in clouds.

[4] Our previous studies have shown that the level of natural aerosol abundance plays an important role in the first aerosol indirect effect. The magnitude of the first indirect forcing is determined by the percentage increase of cloud drop number concentration. Chuang et al. [1997] used different approaches for the formation of anthropogenic sulfate and its relation to aerosol size distribution and estimated that the first indirect forcing by anthropogenic sulfate may range from -0.6 to $-1.6 \mathrm{~W} \mathrm{~m}^{-2}$. This range reduced to -0.4 to $-1.1 \mathrm{~W} \mathrm{~m}^{-2}$ if a prescribed marine background particle number concentration simulating sea salt was universally applied over the oceans. The addition of marine background particles also resulted in a $45 \%$ global reduction of the first indirect forcing by anthropogenic carbonaceous aerosols which, unlike anthropogenic sulfate, may more readily add $\mathrm{CCN}$ proportional to their emissions [Penner et al., 1996]. In this case, the estimated forcing was reduced from -4.5 to $-2.5 \mathrm{~W} \mathrm{~m}^{-2}$. Both works did not account for the aerosol component that arises from dust. In this paper, we refine our previous studies with an improved version of the fully coupled climate/chemistry models described by Chuang et al. [1997]. The updated chemistry model GRANTOUR is now able to calculate the global concentrations of sulfate, dust, sea salt, and carbonaceous aerosols (biomass smoke and fossil fuel organic matter and black carbon). The climate model that was originally developed from the NCAR CCM1 has also been enhanced by a unique capability to take into account the absorption of solar radiation by black carbon within cloud drops. Black carbon is distinguished by its resistance to chemical and thermal attack and by its ability to strongly absorb solar radiation. This ability lowers the single scattering albedo of aerosols, thereby reducing the amount of solar radiation reflected by the aerosols. The presence of black carbon in clouds may also reduce cloud albedo. Observations of the Indian Ocean Experiment (INDOEX) suggest that absorption of solar radiation by soot (black carbon) can significantly reduce the cloud coverage and liquid water path of trade cumulus [Ackerman et al., 2000]. Here, we develop a parameterization for the single scattering albedo of cloud as a function of cloud drop size and the volume fraction of black carbon inside the drop for each wavelength band in our shortwave radiation module. We have also updated this solar radiation package with a higher spectral resolution; nine wavelength bands for the UV Visible wavelength and three for the near-IR spectral range [Penner et al., 1998; Grant et al., 1999]. The effect of black carbon absorption in clouds as well as its impact on the first indirect forcing will be addressed in this study.

[5] To explore the impact of aerosols on climate, one needs not only to take into account all of the important aerosol components derived from both anthropogenic and natural sources but also to identify their roles in the forcing mechanism and to quantify the associated uncertainties. In order to identify the role of natural aerosol abundance in the assessment of the first aerosol indirect effect, we examine the mechanisms that link aerosol sources to cloud drop number concentrations. Since the tropospheric lifetimes of aerosols and their precursor gases are short and the ranges of aerosol loading vary between the continents and oceans, the mechanisms describing these links vary spatially and temporally. It is thus important to study the sensitivity of radiative forcing to the aerosol characteristics and global concentrations in order to place the estimate of aerosol effects on a much more quantitative foundation than is available at present.

\section{Basic Model Descriptions}

[6] We use the fully coupled climate/chemistry models together with specified emissions inventories to simulate global aerosol distributions. The climate model employed here is based on the NCAR CCM1 with modifications similar to those described by Charlock and Ramanathan [1985]. In addition, the solar radiation package in CCM1 has been replaced by a delta-Eddington two-stream approximation. We have implemented a parameterization for the single 
scattering albedo of cloud as described in section 4, and a parameterization for cloud drops as given in section 5 . The model has 12 vertical levels and R15 (rhomboidal truncation at wave number 15) horizontal resolution, which yields an equivalent grid mesh of $4.5^{\circ}$ latitude by $7.5^{\circ}$ longitude. The simulation time interval is $30 \mathrm{~min}$. Surface temperatures are calculated over land, snow and sea ice via a surface energy budget equation, while the sea surface temperatures (SST) over the open ocean are prescribed by climatological data. The model forms stratiform clouds wherever stable condensation occurs, while convective clouds are formed when one or more layers undergo moist convective adjustment. The model assumes that the clouds in each layer are randomly overlapped with a maximum cloud cover of $30 \%$ in a column undergoing moist convection [Kiehl et al., 1987]. Unlike the original NCAR model, the fractional cloud cover for stratiform clouds is prescribed to be $100 \%$ instead of $95 \%$ to simplify the treatment of radiation for stratiform clouds [Taylor and Ghan, 1992]. If the atmosphere is supersaturated the moisture field is adjusted to the level of saturation and the excess goes into clouds that then precipitate. The cloud parameterization and other physical processes are described in detail by Williamson et al. [1987].

[7] The chemistry model GRANTOUR is a Lagrangian parcel model which treats the global-scale transport, transformation, and removal of trace species in the atmosphere [Walton et al., 1988; Penner et al., 1991; Chuang et al., 1997]. The model uses a split-operator method with a 6hour time step to compute the separate effects of sources, chemistry, interparcel mixing, large-scale diffusion, vertical mixing by moist convection, precipitation scavenging and deposition, dry deposition, and advection upon the timedependent parcel mixing ratios (see Penner et al. [1991] for a full description of how these processes are implemented). The climate model is integrated forward in time for 12 hours. The meteorology fields from CCM1 are averaged over this 12-hour period for subsequent use by the GRANTOUR model that is then integrated forward in time for the next 12 hours.

\section{Aerosol Sources and Concentrations}

\subsection{Particulate Sulfate}

[8] Model calculation of the tropospheric sulfate abundance requires reactive sulfur emissions from five main sources: production of (mainly) dimethylsulfide (DMS) in the oceans by phytoplankton, volcanic emissions of sulfur dioxide $\left(\mathrm{SO}_{2}\right)$, terrestrial emissions of DMS and hydrogen sulfide $\left(\mathrm{H}_{2} \mathrm{~S}\right)$ from soils, forests and crops, biomass burning emissions of $\mathrm{SO}_{2}$, and fossil fuel and industrial emissions of $\mathrm{SO}_{2}$. In all cases, the inventories derived by Spiro et al. [1992] and Benkovitz [1982] for calendar year 1980 are used, except for the ocean emissions of DMS. For ocean emissions the inventory from Spiro et al. [1992] is doubled. The doubled emissions reflect the midrange of estimates in the current literature (10 to $40 \mathrm{Tg} \mathrm{S} \mathrm{yr}^{-1}$ ) [Andreae and Raemdonck, 1983; Bates et al., 1987; Erickson et al., 1991; Spiro et al., 1992] and also provide a better comparison with remote measurements of $\mathrm{SO}_{4}^{2-}$ [Penner et al., 1994]. This emissions data set is also similar to a recent evaluation of the DMS flux which uses the average of Liss and Merlivat [1986] and Wanninkhof [1992] parameterizations for the dependence of DMS flux on wind speed and total $24 \mathrm{Tg} \mathrm{S}$ $\mathrm{yr}^{-1}$ [Kettle et al., 1999]. The emissions database for anthropogenic sulfur compounds is about $16 \%$ higher than that developed recently for 1985 [Benkovitz et al., 1996]. However, the use of the 1980 inventory is consistent with our database for fossil fuel emissions of black carbon [Penner et al., 1993] and the database for biomass burning emissions [Liousse et al., 1996]. The prescribed annual source strength and budget for sulfur compounds and other aerosol components are listed in Table 1. (Emission files used in this study are available through the Journal of Geophysical Research Electronic Supplement.) All emissions are presented as monthly averages except for sources from fossil fuel and volcanic eruptions where annual averages are applied. Emissions of surface-based $\mathrm{SO}_{2}$ are input into the model with a constant mixing ratio in the lowest $100 \mathrm{hPa}$, while emissions of volcanic $\mathrm{SO}_{2}$ are grouped into three categories by the height of eruption and are input into the lowest 300,500 , and $700 \mathrm{hPa}$, respectively. The chemical processes and treatments that convert $\mathrm{SO}_{2}$ to $\mathrm{SO}_{4}^{2-}$ are described in detail by Chuang et al. [1997].

[9] In Figures $1 \mathrm{a}$ and $1 \mathrm{~b}$ we present the simulated surface mass concentrations of sulfate converted from anthropogenic (fossil fuel and industry, biomass burning) and natural (terrestrial soils, forests, oceans, volcanoes) sources of $\mathrm{SO}_{2}$, respectively. We may note that the majority of anthropogenic $\mathrm{SO}_{2}$ is from fossil fuel and industry in the northern hemisphere with a maximum over Europe, followed by the eastern United States and China. Contrary to the anthropogenic sources, the natural sources are strongly seasonally dependent and distributed roughly evenly between the two hemispheres. Since summer is the main season for sulfate production through photochemical reactions, the sulfate concentration is much higher in summer compared to winter. Besides the photochemical production rate, the precipitation is also an important factor in determining the local sulfate concentration. Our simulation indicates that the higher sulfate concentrations over China in January are mainly attributed to a lower precipitation rate as compared to those in Europe and the eastern United States.

[10] In addition to the model/data comparisons we have shown previously [Penner et al., 1994], we also compare the model results with aerosol concentrations measured at a number of locations that are part of a larger ocean network operated by a group at the University of Miami [Prospero et al., 1989; Savoie et al., 1989, 1993; Arimoto et al., 1995]. These measuring sites, given in Figure 1a.1, are located at coastal sites on the climatological windward shore of islands or continental coastlines. Samples are collected by drawing air through large area filters at a flow rate of about $1 \mathrm{~m}^{3} \mathrm{~min}^{-1}$. At Cape Grim filters were exposed continuously for 1-week periods. At Midway, American Samoa, Mace Head, and Barbados the samplers were electronically controlled so that they were only activated when the wind came directly from over the open ocean and when the wind speed was greater than $1 \mathrm{~m} \mathrm{~s}^{-1}$. The Midway and American Samoa sites operated on a weekly protocol while Mace Head and Barbados were on a daily schedule. Direct comparison with measurements is difficult, not only because the chemistry model uses 12-hour averaged meteorology fields but also because model results are interpreted as the average of each GCM grid cell $\left(4.5^{\circ}\right.$ latitude by $7.5^{\circ}$ longitude) such 
Table 1. Prescribed Source Strength and Budget for Aerosols and Precursor Gases

\begin{tabular}{|c|c|c|c|}
\hline & $\mathrm{SH}$ & $\mathrm{NH}$ & Global \\
\hline \multicolumn{4}{|c|}{$\mathrm{SO}_{2}, \mathrm{TgS} \mathrm{Syr}^{-1}$} \\
\hline \multicolumn{4}{|l|}{ Sources: } \\
\hline \multicolumn{4}{|l|}{ Emissions } \\
\hline Fossil fuel and industry & 8.02 & 67.70 & 75.72 \\
\hline Biomass burning & 0.98 & 1.25 & 2.24 \\
\hline Volcanoes & 1.12 & 2.25 & 3.37 \\
\hline \multicolumn{4}{|l|}{ Photochemistry } \\
\hline Terrestrial soils, forests, etc. & 0.33 & 0.54 & 0.88 \\
\hline Ocean DMS & 13.09 & 10.55 & 23.64 \\
\hline \multicolumn{4}{|l|}{ Sinks: } \\
\hline Dry deposition & 6.42 & 32.19 & 38.62 \\
\hline Wet deposition & 2.58 & 13.10 & 15.69 \\
\hline $\mathrm{OH}$ oxidation & 1.55 & 4.89 & 6.44 \\
\hline Aqueous oxidation & 12.69 & 32.51 & 45.20 \\
\hline Burden, Tg S & 0.05 & 0.29 & 0.34 \\
\hline Turnover time, days & 0.78 & 1.29 & 1.17 \\
\hline \multicolumn{4}{|c|}{$\mathrm{SO}_{4}^{2-}, \mathrm{TgS} y r^{-1}$} \\
\hline \multicolumn{4}{|l|}{ Sources: } \\
\hline $\mathrm{OH}$ oxidation & 1.55 & 4.89 & 6.44 \\
\hline Aqueous oxidation & 12.69 & 32.51 & 45.20 \\
\hline \multicolumn{4}{|l|}{ Sinks: } \\
\hline Dry deposition & 1.40 & 4.27 & 5.66 \\
\hline Wet deposition & 12.85 & 33.13 & 45.97 \\
\hline Burden, Tg S & 0.20 & 0.43 & 0.63 \\
\hline Turnover time, days & 5.13 & 4.20 & 4.45 \\
\hline
\end{tabular}

Organic Matter, $T g y^{-1}$

\section{Sources: \\ Emissions \\ Fossil fuel \\ Biomass burning \\ Photochemistry \\ Terpenes \\ Sinks: \\ Dry deposition \\ Wet deposition \\ Burden, Tg}

Turnover time, days

$\begin{array}{rrr}0.40 & 30.14 & 30.54 \\ 21.73 & 23.91 & 45.65\end{array}$

$\begin{array}{lll}7.90 & 8.84 & 16.74\end{array}$

\begin{tabular}{ll}
$5.41 \quad 13.55$ \\
\hline
\end{tabular}

$23.39 \quad 50.55$

$0.62 \quad 1.00$

$7.54 \quad 5.80$

Black Carbon, $\operatorname{Tg~}_{y}{ }^{-1}$

18.96

73.94

1.62

6.36

(3)

3.2

Table 1. (continued)

\begin{tabular}{|c|c|c|c|}
\hline & SH & $\mathrm{NH}$ & Global \\
\hline \multicolumn{4}{|c|}{ Small Sea Salt $(<2 \mu m), \operatorname{Tg}_{y r^{-1}}$} \\
\hline \multicolumn{4}{|c|}{ 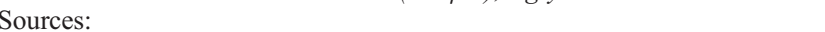 } \\
\hline Emissions & 56.31 & 25.79 & 82.11 \\
\hline Dry deposition & 17.80 & 7.68 & 25.48 \\
\hline Wet deposition & 36.07 & 20.70 & 56.77 \\
\hline Burden, Tg & 0.91 & 0.47 & 1.38 \\
\hline Turnover time, days & 5.89 & 6.65 & 6.13 \\
\hline \multicolumn{4}{|c|}{ Large Sea Salt $(2-20 \mu \mathrm{m}), \quad \operatorname{Tg}_{y} r^{-1}$} \\
\hline Sources: & & & \\
\hline Emissions & 1771.93 & 811.65 & 2583.58 \\
\hline \multicolumn{4}{|l|}{ Sinks: } \\
\hline Dry deposition & 1404.46 & 635.37 & 2039.84 \\
\hline Wet deposition & 344.90 & 201.14 & 546.04 \\
\hline Burden, Tg & 4.00 & 1.87 & 5.88 \\
\hline Turnover time, days & 0.82 & 0.84 & 0.83 \\
\hline
\end{tabular}

that the simulated wind direction and wind speed resolved by the GCM may not be consistent with those at the measuring site. However, these comparisons can serve as a reference to determine, in part, the accuracy of our simulated aerosol concentrations. As shown in Table 2, most of the simulated concentrations are within one standard deviation of the mean of the measurements, but simulations that deviate more than one standard deviation do exist in some locations. For example, the model transports too little sulfate from Asian sources to the North Pacific Ocean and misses the spring peak at Midway. The model also predicts too much sulfate at Cape Grim in the summer time. The predicted seasonality at American Samoa and Barbados is reasonable but the simulated concentrations are always lower than the mean of the measurements. Some of this discrepancy may be attributed to a DMS source that is too small, since the uncertainty in air-sea transfer rates may allow a source that is as much as 50\% larger [Kettle and Andreae, 2000].

\subsection{Carbonaceous Particles}

[11] Carbonaceous aerosols are usually divided into two fractions: organic carbon (OC) and black carbon (BC). OC represents a fraction of the total organic matter $(\mathrm{OM})$ present in the particle. OM is a measure of the total mass chemically bound to carbon and therefore includes, in addition to carbon, hydrogen atoms, oxygen atoms, and minor amounts of other species. Anthropogenic carbonaceous aerosols are mainly from sources such as biomass burning and fossil fuel combustion. Natural organic particles come from photochemical conversion of gaseous emissions from vegetation as well as from direct emissions of particles from plants. Our emissions inventories for $\mathrm{BC}$ and $\mathrm{OM}$ from fossil fuel combustion are those developed by Penner et al. [1993] (where $\mathrm{OM}$ is assumed to be proportional to $\mathrm{BC}$ with a factor of 4.6), whereas the inventories developed by Liousse et al. [1996] for total biomass particles (TP) are used to derive the emissions of $\mathrm{BC}$ and $\mathrm{OM}$ from biomass burning. The particles produced by biomass burning are a complex mixture of $\mathrm{BC}, \mathrm{OM}$ and other constituents (nitrates, sulfates, etc.). Following Liousse et al. [1996], it is assumed that 85\% of the non-black carbon biomass particles, i.e., (TP-BC), is organic matter.

[12] The magnitude of the source of natural organic particles from photochemical oxidation of naturally emitted 

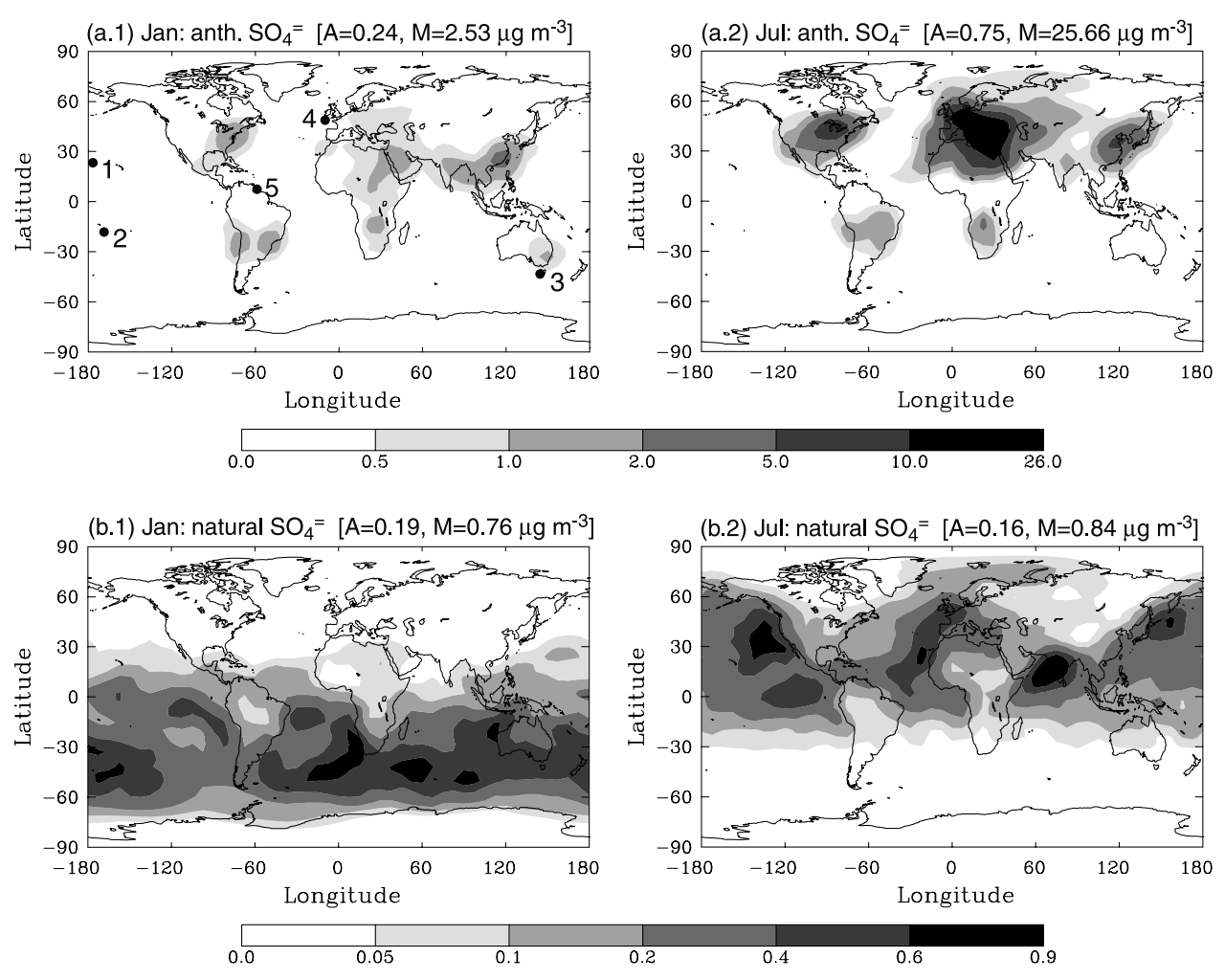

Figure 1. Simulated surface mass concentrations of nss-sulfate converted from (a) anthropogenic and (b) natural sources of $\mathrm{SO}_{2}$. Values shown in bracket are the global average A and the maximum M. Also shown in Figure 1a.1 are five locations where simulated concentrations are compared to measurements in Table 2.

volatile organic species depends on both the species that are emitted and the oxidation path in the atmosphere. Oxidation of naturally emitted terpenes can lead to the formation of compounds with low volatility as well as compounds that are semivolatile. Smog chamber experiments have been interpreted as providing aerosol production yields that depend heavily on the oxidation mechanism [Hoffmann et al., 1997], with most of the low volatility products apparently produced during reactions with $\mathrm{O}_{3}$ or $\mathrm{NO}_{3}$. Oxidation by $\mathrm{OH}$ most often leads to semivolatile compounds that would not remain in the aerosol phase on the larger scales considered here. The specific terpene emitted is also an important factor in determining the aerosol production. Smog chamber experiments [Hoffmann et al., 1997] lead to aerosol yields of $5 \%$ for open-chained hydrocarbons, $5-25 \%$ for monounsaturated cyclic monoterpenes, and $40 \%$ for a cyclic monoterpene with two double bonds. These yields include the production of both low volatility products as well as semivolatile products that form aerosols under the conditions of the experiment.

[13] Thus, in order to determine aerosol yields, the initial oxidation step is needed as well as the type of terpene, and the fraction of low volatile and semivolatile products. More specifically, in order to estimate aerosol yield under varying conditions, one needs an estimate of the semivolatile products and their vapor pressure. Unfortunately, no generally available inventory for emissions of different terpene compounds is readily available, nor are products and vapor pressures for the products of each terpene which is emitted and oxidized available. However, Guenther et al. [1995] estimated the global emissions of monoterpenes equal to
$127 \mathrm{Tg} \mathrm{C} \mathrm{yr}^{-1}$. The specific compounds emitted are expected to vary by region; however, regionally, monoterpene emissions are largest in the tropics and subtropics [Guenther et al., 1995]. A. Guenther (private communication, 1998) estimated that the average magnitude of different terpenes emitted in tropical and subtropical landscapes might be $\alpha$-pinene: 35\%; $\beta$-pinene, myrcene, and limonene: $10 \%$ each; camphene, 3 -carene, and terpinolene: $5 \%$ each; p-cymene and tricyclene: $2 \%$ each; cineole, $\alpha$-terpinene, $\gamma$-terpinene, $\alpha$-thujene, sabinene, and t-ocimene: $1 \%$ each; all sesquiterpenes: $1.5 \%$; with $8.5 \%$ undifferentiated terpenes. The vast majority of these emissions represent monoterpenes, so we used these fractional emissions together with the monoterpene inventory from Guenther et al. [1995] and the aerosol yields from Hoffmann et al. [1997] to estimate the total yield of low-volatile aerosol products formed. These low volatility products are assumed to remain in the aerosol phase even on global scales. Based on the model calculations of Penner et al. [1994], we estimate that roughly half of the emitted terpenes react with $\mathrm{OH}$ rather than with $\mathrm{O}_{3}$ or $\mathrm{NO}_{3}$. Because the study of Hoffmann et al. [1997] showed that the reaction with $\mathrm{OH}$ tends to lead to products that are more volatile than the products derived from reaction with $\mathrm{O}_{3}$ or $\mathrm{NO}_{3}$, we assumed that only about half of the total yield of aerosol in the experiments summarized by Hoffmann et al. [1997] remain as an aerosol product on the global scale. Moreover, we assume that all of the terpenes emitted react on short timescales compared to the time to transport these to the larger global scales of concern here. Thus, we estimated the total source strength of aerosols from terpene oxidation as 
Table 2. Simulated Aerosol Surface Concentrations ${ }^{\mathrm{a}}$ Versus Measurements ${ }^{\mathrm{b}}$

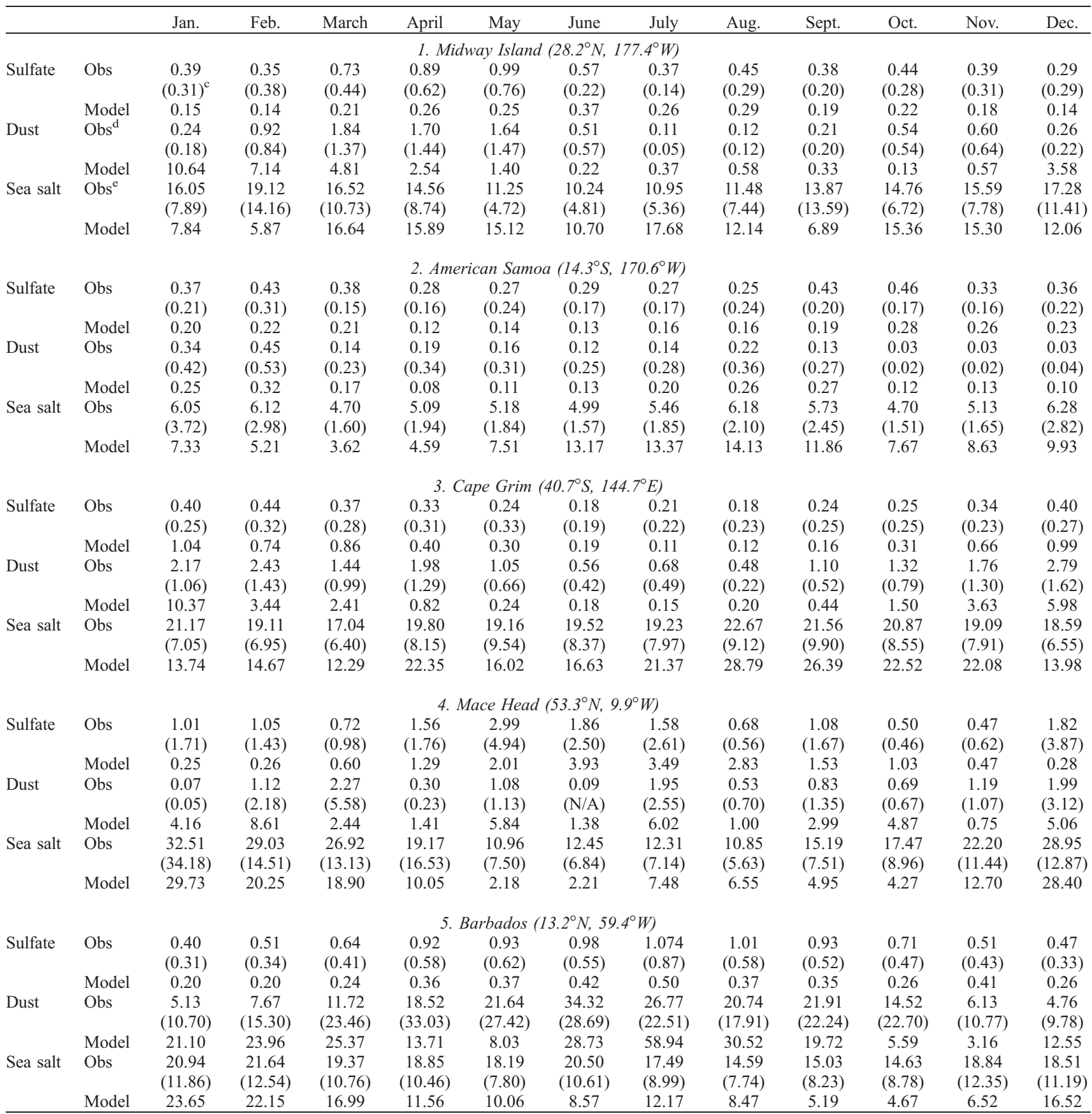

${ }^{\mathrm{a}}$ Model results for dust and sea salt include both size categories (i.e., $0-2$ and $2-20 \mu \mathrm{m}$ ).

${ }^{\mathrm{b}}$ Measured data were compiled by D. L. Savoie and J. M. Prospero (private communication, 2000). Locations of measuring sites are shown in Figure 1a.1.

${ }^{c}$ Value in parenthesis is the standard deviation of the measurements.

${ }^{\mathrm{d}}$ Dust data were derived from the measured aluminum mass concentrations assuming $8 \%$ of dust concentration is aluminum.

${ }^{\mathrm{e}}$ Sea-salt data were derived from the measured sodium concentrations assuming a Na/sea salt mass ratio of 0.3071 .

the product of the monoterpene emission rate with the sum of the emitted fraction of each terpene times one half the total aerosol yield estimated by Hoffmann et al. [1997] for each fraction. The sum of the product of the emitted fraction with half the aerosol yield leads to a total large scale aerosol yield from terpene oxidation of $12 \%$, which, for the monoterpene emissions of Guenther et al. [1995] corresponds to an average total source strength of $16 \mathrm{Tg} \mathrm{yr}^{-1}$ with an uncertain range from 8 to $40 \mathrm{Tg} \mathrm{yr}^{-1}$ [Penner et al., 1999; see also Griffin et al., 1999]. Here, we scaled the mono- terpene source inventory of Guenther et al. [1995] by the yield factor $(12 \%)$ to estimate the source of natural organic particles. We will examine in a later section the uncertainty of the first indirect forcing associated with uncertainties in the emissions of biogenic volatile organics and the production of aerosols from these compounds.

[14] Our model procedures for carbonaceous particles follow those developed by Liousse et al. [1996]. For emissions from fossil fuel, domestic fires and natural sources that are injected into the boundary layer, we use a simplified 

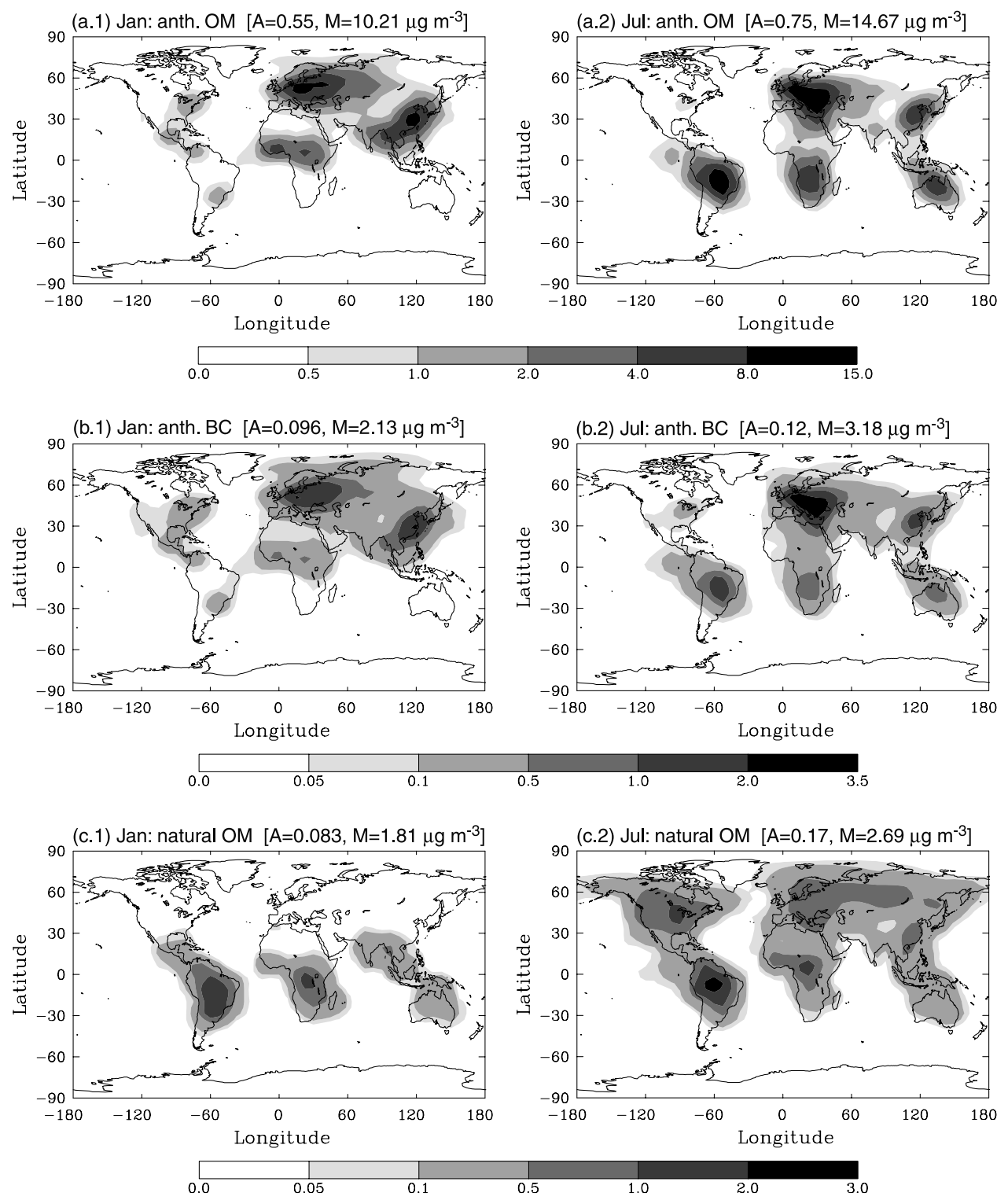

Figure 2. Simulated surface mass concentrations of (a) anthropogenic organic matter, (b) anthropogenic black carbon, and (c) natural organic matter derived from the oxidation of terpenes. Values shown in bracket are the global average $\mathrm{A}$ and the maximum $\mathrm{M}$.

treatment in which particles are input into the model with a vertical profile that is assumed to be constant in mixing ratio in the lowest $100 \mathrm{hPa}$. Emissions from savanna, forest and open-fire agricultural fires are injected to the free troposphere as a result of the buoyancy developed by the heat of the fire and by the daytime convection and are therefore input into the lowest $200 \mathrm{hPa}$. Our simulated global distributions of carbonaceous aerosols from anthropogenic and natural sources are presented in Figure 2. These distributions essentially reflect the distributions of sources as noted earlier [Liousse et al., 1996]. As shown in Figures 2b.1 and 2b.2 our model predicts a low BC concentration, $0.1-0.5 \mu \mathrm{g} \mathrm{m}^{-3}$, over the Indian subcontinent, while BC concentrations measured by aircraft during the intensive field phase (February-March 1999) of the INDOEX range from 0.6 to 6.3 $\mu \mathrm{g} \mathrm{m}^{-3}$ [Mayol-Bracero et al., 2002]. This discrepancy is caused by the low BC emissions over the Indian subcontinent in our 1980 emissions database. Figure 3 shows the observed and simulated surface concentrations of OM and $\mathrm{BC}$ at a number of locations. Since the measured data are presented as $\mathrm{OC}$, for comparison to measurements we assume that $\mathrm{OM} / \mathrm{OC}=1.4$. (We note that the conversion from $\mathrm{OC}$ to $\mathrm{OM}$ is variable - it depends on the molecular structure of $\mathrm{OM}$ in the aerosol.) Comparisons of carbonaceous aerosols to observations are more difficult because the measured concentrations are only available on a campaign basis such that the measured values are subject to short term variability. Such temporal variations may introduce significant discrepancy between the observations and the monthly averaged predictions from the model. Despite these facts, most simulated values are within a factor of 2 of the measurements.

\subsection{Dust Particles}

[15] The simulated global distribution of dust particles is based on a dust emissions model that was originally 

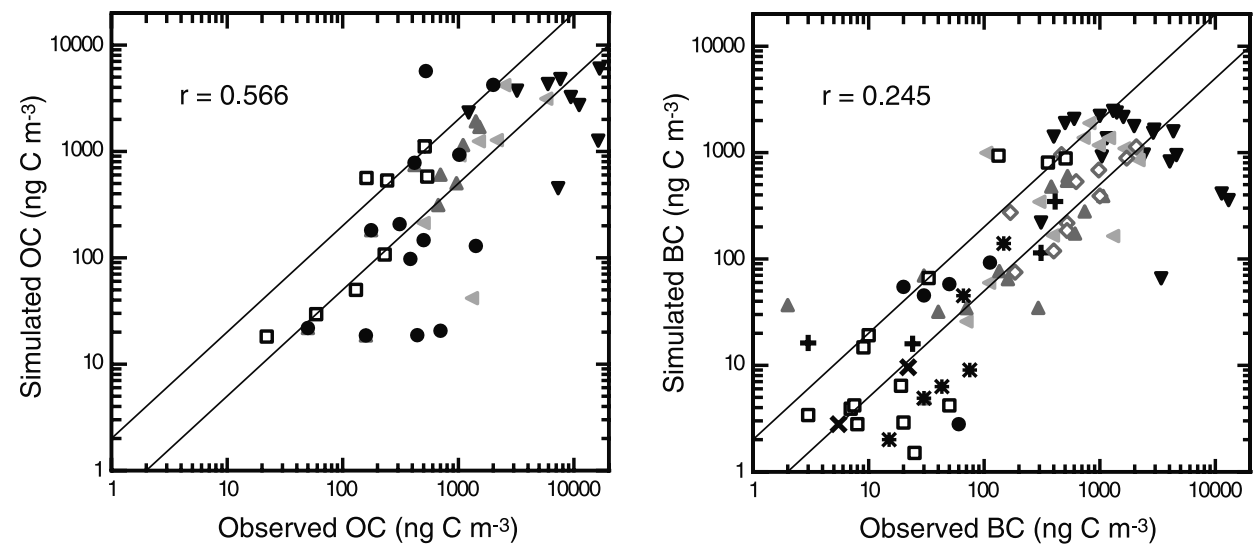

\begin{tabular}{|ll|}
\hline - Liousse_NH & $\Delta$ Cooke_Island \\
$\square$ Liousse_SH & $\triangle$ Cooke_Rural \\
& $\nabla$ Cooke_Urban
\end{tabular}

\begin{tabular}{|ll|}
\hline - Liousse_Atlantic & $\times$ Liousse_SH_Remote \\
口 Liousse_Pacific & $\triangle$ Cooke_Remote \\
$\diamond$ Liousse_NH_Rural & $\triangle$ Cooke_Rural \\
+ Liousse_SH_Rural & $\nabla$ Cooke_Urban \\
* Liousse_NH_Remote &
\end{tabular}

Figure 3. Observed and simulated surface concentrations of organic carbon (in $\mathrm{ngC} \mathrm{m} \mathrm{m}^{-3}$ ) and black carbon (in $\mathrm{ngC} \mathrm{m}^{-3}$ ) at a number of locations. Observations refer to those summarized by Liousse et al. [1996] and Cooke et al. [1999]. Correlation between the measured and modeled values is represented by the coefficient $r$. Two thin lines represent the range above and below the observed values by a factor of 2 .

developed by Rau et al. [1994] and previously described by Lohmann et al. [1999]. This dust model uses an algorithm to relate monthly mean wind speed to monthly dust source strength, which includes a correction for the stochastic variation of wind about its mean, and computes the dust flux to be proportional to the fourth power of the surface friction velocity. Dust source regions are identified from the $1^{\circ} \times 1^{\circ}$ soil moisture data of Webb et al. [1993] as those areas that perennially contain $<15 \mathrm{~mm}$ soil water. This data set was based on 1971-1981 Soil Map of the World and the World Soil Data File [Zobler, 1986], in conjunction with the global vegetation data set of Matthews [1983]. Since dust particles with diameter $(d)$ larger than $20 \mu \mathrm{m}$ are not important for long range transport, only particles smaller than $20 \mu \mathrm{m}$ are considered here and divided into two size categories, small particles $(d<2 \mu \mathrm{m})$ and large particles $(2<d<20 \mu \mathrm{m})$. The use of monthly mean sources with time varying winds may lead to an underestimate of dust variability but should provide a reasonably accurate estimate of monthly mean concentrations as long as the effect of the variability of the winds on the monthly mean sources is taken into account as we do here. [We note that the use of low resolution GCM wind fields to predict dust mobilization would be impractical since most such winds do not capture the observed wind variability in any case.] The global dust source strength is estimated to be about $5102 \mathrm{Tg} \mathrm{yr}^{-1}$ with $243 \mathrm{Tg} \mathrm{yr}^{-1}$ for small particles and $4859 \mathrm{Tg} \mathrm{yr}^{-1}$ for large particles. This value is near the upper limit of the range estimated by previous authors, 200 to $5000 \mathrm{Tg} \mathrm{yr}^{-1}$ [Goudie, 1983; Duce, 1995]. Tegen and Fung [1994] gave a modeled global dust source strength of $3000 \mathrm{Tg} \mathrm{yr}^{-1}$ that was lowered to $1500 \mathrm{Tg} \mathrm{yr}^{-1}$ in a later treatment [Tegen et al., 1996]. As in previous observations and models, the vast majority of dust in our model is generated in the Northern Hemisphere $(98 \%)$ with large particles contributing $95 \%$ of the total Northern Hemisphere dust flux (see Table 1).
[16] The dust emissions data together with our coupled models are used to predict the global dust concentrations. Because injection of dust can occur over deep atmospheric layers, especially in the larger dust storms that we are simulating, we apply a uniform vertical mixing ratio injection between the surface and $600 \mathrm{hPa}$ for small particles, and a linearly decreasing mixing ratio injection to zero at $600 \mathrm{hPa}$ for large particles. The linearly decreasing injection is a simplified method to account for the fact that larger particles are not lifted as easily as small particles. Figure 4 shows the simulated global distribution of surface dust concentrations. It is not surprising that the maximum dust concentration is located in the Sahara desert region in Africa. Simulations show that these African dust particles as measured are transported over the North Atlantic and Caribbean [Prospero, 1999]. Comparisons of the modeled concentrations of total dust particles to observations are also listed in Table 2. It is encouraging that on average the magnitudes of simulated dust concentrations are usually within an order of magnitude of the observations. In most of the site-specific comparisons, the model reasonably well reproduces the major features of the observed seasonal cycle, although at the Northern Pacific location (e.g., Midway) the model overestimates winter dust concentrations. This behavior is apparently associated with the modeled Asian dust source strength that is a factor of 10 larger in winter compared to spring. The large modeled dust fluxes are driven by the winter winds (the fourth power function comes in strong here). Furthermore, the model consistently overestimates dust concentrations at Mace Head.

\subsection{Sea-Salt Particles}

[17] The formulas and procedures that we use to develop sea-salt emissions are given by Lohmann et al. [1999]. The main mechanism for sea-salt generation is via the bursting of whitecap bubbles [Monahan et al., 1986]. The total global strength of sea-salt emissions is estimated to be 

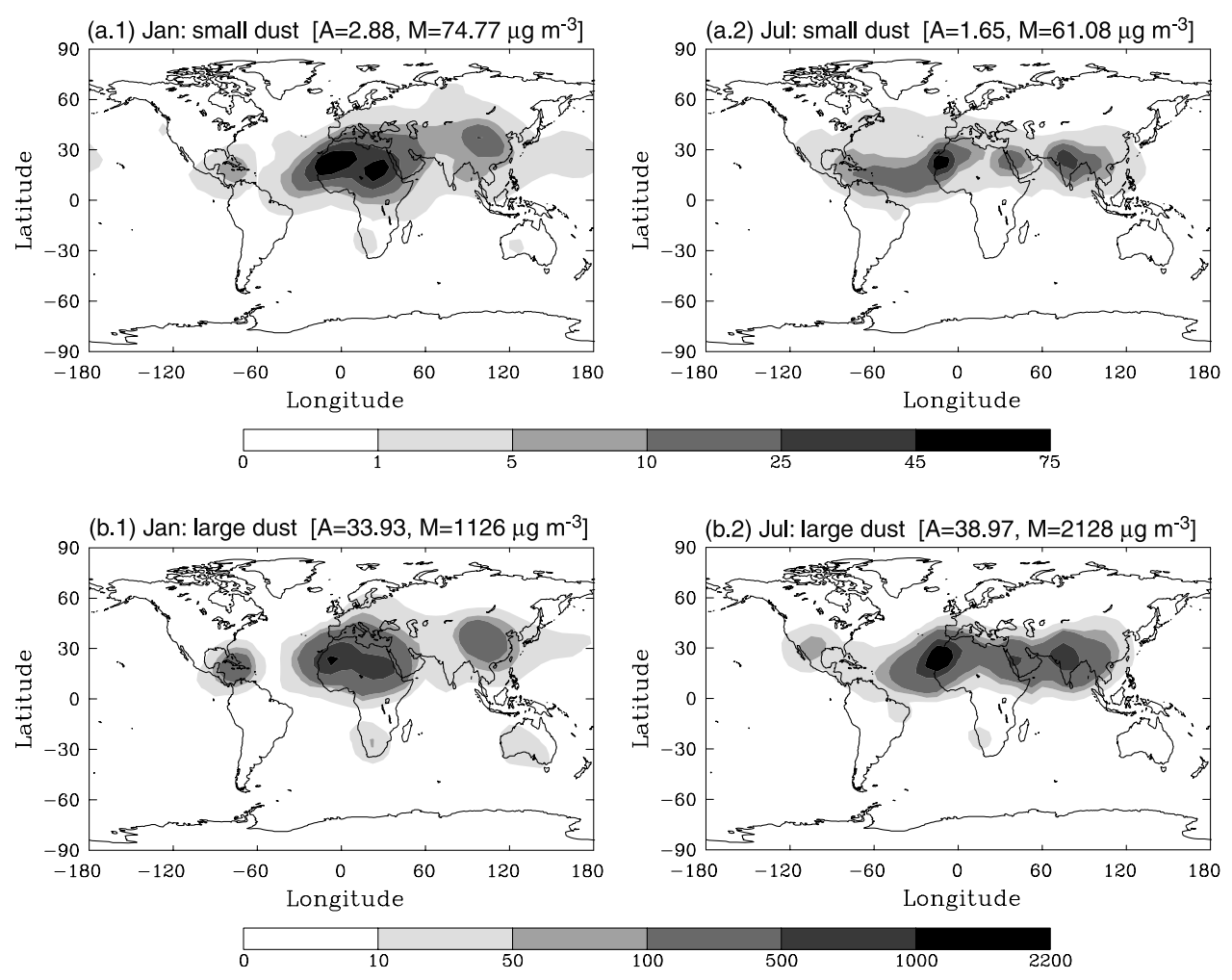

Figure 4. Simulated surface mass concentrations of dust particles with (a) $d<2 \mu \mathrm{m}$ and (b) $2<d<20$ $\mu \mathrm{m}$. Values shown in bracket are the global average A and the maximum M.

$2655 \mathrm{Tg} \mathrm{yr}^{-1}$ with $80 \mathrm{Tg} \mathrm{yr}^{-1}$ for small particles and 2575 $\mathrm{Tg}_{\mathrm{yr}}^{-1}$ for large particles. The sea-salt particles are input into our coupled models with a vertical profile that is assumed to be constant in mixing ratio in the lowest 100 $\mathrm{hPa}$. Figure 5 shows the simulated surface concentrations of sea-salt particles. The maximum is located in a region between $40^{\circ} \mathrm{S}$ and $60^{\circ} \mathrm{S}$ and the total source strength of sea salt is more than twice as large in the southern hemisphere compared to the northern hemisphere. As shown in Table 2, most of the simulated sea-salt concentrations are within one standard deviation of the measured mean but there are locations where the model consistently overestimates the sea-salt concentrations (e.g., American Samoa from May to December). In addition, the model shows a significant seasonal variation at Barbados and Cape Grim whereas the measured data do not show much seasonality. This discrepancy is associated with the nearby source strength that is seasonably variable. The wind speeds used to generate the source may not be consistent with those simulated here. In addition, at Cape Grim the station is at an altitude of several hundred meters and sea-salt concentrations at this site may be dominated by local conditions.

\section{Effect of Black Carbon on Single Scattering Albedo of Cloud}

[18] Carbonaceous aerosols and dust can both act as CCN and thereby change the optical properties of clouds. Each has important absorption characteristics that may reduce the single scattering albedo of cloud drops, therefore reducing the amount of solar radiation reflected by the clouds. Here, our focus is on evaluating the importance of absorption by
$\mathrm{BC}$ in clouds, because our initial studies showed that the first indirect forcing by anthropogenic carbonaceous aerosols may be quite large [Penner et al., 1996]. We have modeled this effect in the following manner.

[19] For a collection of cloud drops with randomly positioned carbon inclusions, the single scattering albedo of the cloud drops can be estimated using an effective medium approximation [Chylek and Videen, 1998]. The dielectric constant of the effective medium can be approximated with the Maxwell Garnett mixing rule [Bohren and Huffman, 1983; Chylek et al., 1988],

$$
m^{2}=m_{\mathrm{o}}^{2} \frac{m_{B C}^{2}+2 m_{\mathrm{o}}^{2}+2 \nu_{d}\left(m_{B C}^{2}-m_{\mathrm{o}}^{2}\right)}{m_{B C}^{2}+2 m_{\mathrm{o}}^{2}-\nu_{d}\left(m_{B C}^{2}-m_{\mathrm{o}}^{2}\right)}
$$

where $m=n+i k(k>0)$ is the refractive index for the drop/ $\mathrm{BC}$ mixture, $m_{\mathrm{o}}$ is the (complex) refractive index of water, $m_{B C}$ is the refractive index of $\mathrm{BC}$, and $v_{d}$ is the volume fraction of BC within the drop. Chylek et al. [1996] demonstrated that if $\mathrm{BC}$ is randomly distributed within the drop, the effective medium approximation is reasonable.

[20] For small volume fractions of BC, using the explicit complex square root to get the components of $m$ from the dielectric constant $m^{2}$ can result in unacceptable truncation. We therefore use an iteration procedure over the index $j$ defined by

$$
\begin{aligned}
& n_{j}=\sqrt{\operatorname{Re}\left(m^{2}\right)+k_{j-1}^{2}} \\
& k_{j}=\operatorname{Im}\left(m^{2}\right) /\left(2 n_{j}\right)
\end{aligned}
$$

until we obtain convergence for $k$. 

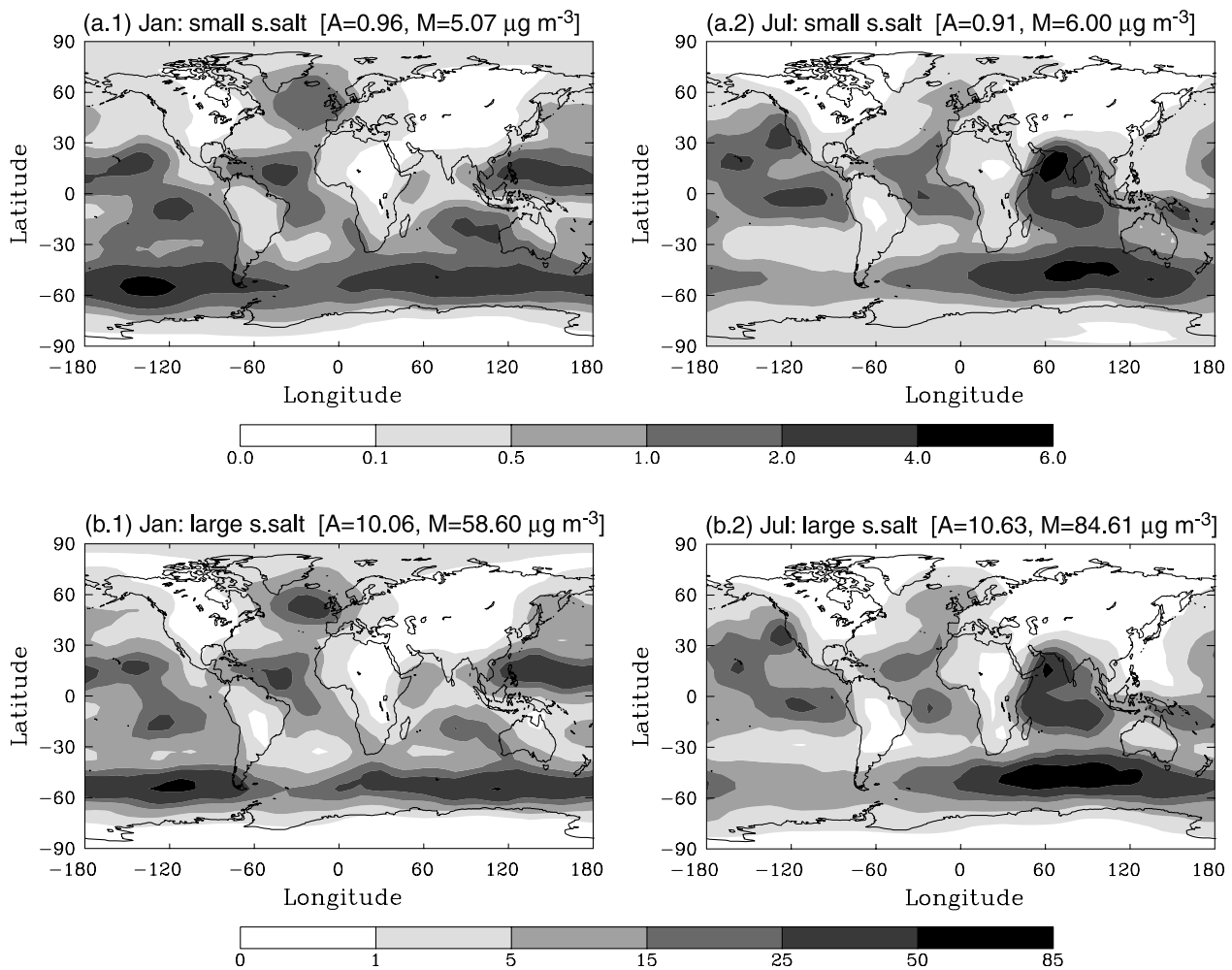

Figure 5. Simulated surface mass concentrations of sea-salt particles with (a) $d<2 \mu$ m and (b) $2<d<$ $20 \mu \mathrm{m}$. Values shown in bracket are the global average A and the maximum $\mathrm{M}$.

[21] Given the refractive index for the drop with embedded $\mathrm{BC}$ particles, we can approximate the single scattering albedo of a cloud drop using the geometric optics. The absorption coefficient for a drop/BC mixture may be approximated by

$$
C_{a b s}=\frac{\pi}{6} d^{3} \frac{\delta}{n}\left[n^{3}-\left(n^{2}-1\right)^{3 / 2}\right]
$$

where $\delta=4 \pi k \lambda, d$ is the diameter of cloud drop, and $\lambda$ is the wavelength of light [Bohren and Huffman, 1983]. Since the extinction coefficient is $C_{\text {ext }}=\pi d^{2} / 2$, the single scattering co-albedo $(\varpi)$ is expressed by $\left[C_{a b s} / C_{e x t}\right]$. In practice, this approximation only holds if $d \delta \ll 1$, which fails to be true for typical $\mathrm{BC}$ inclusions in cloud drops $\left(\nu_{d} \approx 10^{-7}\right)$ in the wavelength region where $\lambda>2 \mu \mathrm{m}$. Fortunately, in this region absorption by water dominates that by BC, such that a smooth fit between the co-albedo predicted above and that from pure water provides a sufficiently accurate approximation. By comparison with the single scattering albedo tables by Stephens [1979], we develop an empirical approximation,

$$
C_{a b s}=\frac{\frac{\pi}{6} d^{3} \delta n^{2}\left[1-\left(1-n^{-2}\right)^{3 / 2}\right]}{1+0.8 d \delta}
$$

In the limit of $d \delta \gg 1$, this expression reduces to a single scattering co-albedo given by

$$
\varpi=\frac{5}{12} n^{2}\left[1-\left(1-n^{-2}\right)^{3 / 2}\right]
$$

[22] These optical properties are averaged over each wavelength band in the radiation model, and we end up with an expression for the single scattering co-albedo wherein:

$$
\varpi\left(v_{d}, d_{\mathrm{o}}\right)=\varpi_{\mathrm{o}}+\beta_{1}\left[1-\mathrm{e}^{-\beta_{3}\left(\nu_{d}-\nu_{\mathrm{o}}\right)}\right]+\beta_{2}\left[1-\mathrm{e}^{-\beta_{4}\left(\nu_{d}-\nu_{\mathrm{o}}\right)}\right]
$$

where $d_{\mathrm{o}}=20 \mu \mathrm{m}, \nu_{\mathrm{o}}=10^{-8}$, and $\varpi_{\mathrm{o}}$ is the single scattering co-albedo for a $20 \mu \mathrm{m}$ cloud drop without black carbon. In Table 3, we list the values of $\varpi_{\mathrm{o}}$ and parameters $\beta$ for a drop/BC mixture with diameter $20 \mu \mathrm{m}$.

[23] It may be noticed that for a given value of $\nu_{d}$ the absorption by a drop/BC mixture is roughly proportional to the drop size. Thus, the single scattering co-albedo of a drop/BC mixture with diameter $d$ is approximated by

$$
\varpi\left(v_{d}, d\right)=\frac{\frac{d}{d_{\mathrm{o}}} \varpi\left(v_{d}, d_{\mathrm{o}}\right)}{1+1.8 \varpi\left(\nu_{d}, d_{\mathrm{o}}\right)\left[\frac{d}{d_{\mathrm{o}}}-1\right]}
$$

where the single scattering albedo $\omega\left(\nu_{d}, d\right)=1-\varpi\left(\nu_{d}, d\right)$. Figure 6 shows the variations of the single scattering albedo and co-albedo with volume BC fraction and wavelength for different sizes of cloud drops. These approximations have been incorporated into our climate model to evaluate the impact of absorbing particles on the first indirect forcing.

\section{Cloud Drop Parameterization}

[24] A critical link between clouds and aerosols is the nucleation process, in which supersaturation activates some 
Table 3. Coefficients of Single Scattering Co-Albedo for a Drop/BC Mixture With $d=20 \mu \mathrm{m}$

\begin{tabular}{|c|c|c|c|c|c|}
\hline Wavelength $(\mu \mathrm{m})$ & $\varpi_{0}$ & $\beta_{1}$ & $\beta_{2}$ & $\beta_{3}$ & $\beta_{4}$ \\
\hline $0.1754-0.2247$ & $5.189239 \mathrm{e}-05^{\mathrm{a}}$ & $2.382803 \mathrm{e}-01$ & $2.940957 \mathrm{e}-01$ & $6.183657 \mathrm{e}+01$ & $5.742111 \mathrm{e}+02$ \\
\hline $0.2247-0.2439$ & $2.261712 \mathrm{e}-05$ & $2.400113 \mathrm{e}-01$ & $2.936845 \mathrm{e}-01$ & $5.825082 \mathrm{e}+01$ & $5.650809 \mathrm{e}+02$ \\
\hline $0.2439-0.2857$ & $1.264190 \mathrm{e}-05$ & $2.471480 \mathrm{e}-01$ & $2.880274 \mathrm{e}-01$ & $5.279042 \mathrm{e}+01$ & $5.190711 \mathrm{e}+02$ \\
\hline $0.2857-0.2985$ & $9.446845 \mathrm{e}-06$ & $2.489583 \mathrm{e}-01$ & $2.871209 \mathrm{e}-01$ & $5.006907 \mathrm{e}+01$ & $4.940088 \mathrm{e}+02$ \\
\hline $0.2985-0.3225$ & $6.090293 \mathrm{e}-06$ & $2.542476 \mathrm{e}-01$ & $2.824498 \mathrm{e}-01$ & $4.575322 \mathrm{e}+01$ & $4.483519 \mathrm{e}+02$ \\
\hline $0.3225-0.3575$ & $3.794524 \mathrm{e}-06$ & $2.588392 \mathrm{e}-01$ & $2.775943 \mathrm{e}-01$ & $4.243440 \mathrm{e}+01$ & $4.099063 \mathrm{e}+02$ \\
\hline $0.3575-0.4375$ & $1.735499 \mathrm{e}-06$ & $2.659081 \mathrm{e}-01$ & $2.698008 \mathrm{e}-01$ & $3.703823 \mathrm{e}+01$ & $3.489051 \mathrm{e}+02$ \\
\hline $0.4375-0.4975$ & $1.136807 \mathrm{e}-06$ & $2.700860 \mathrm{e}-01$ & $2.652968 \mathrm{e}-01$ & $3.232349 \mathrm{e}+01$ & $2.979909 \mathrm{e}+02$ \\
\hline $0.4975-0.6925$ & $2.261422 \mathrm{e}-06$ & $2.783093 \mathrm{e}-01$ & $2.564840 \mathrm{e}-01$ & $2.599426 \mathrm{e}+01$ & $2.337397 \mathrm{e}+02$ \\
\hline $0.6925-0.8621$ & $1.858815 \mathrm{e}-05$ & $2.814346 \mathrm{e}-01$ & $2.535739 \mathrm{e}-01$ & $2.005043 \mathrm{e}+01$ & $1.754385 \mathrm{e}+02$ \\
\hline $0.8621-2.2727$ & $5.551822 \mathrm{e}-03$ & $2.822860 \mathrm{e}-01$ & $2.487382 \mathrm{e}-01$ & $1.276966 \mathrm{e}+01$ & $1.128208 \mathrm{e}+02$ \\
\hline $2.2727-3.8462$ & $2.325124 \mathrm{e}-01$ & $1.797007 \mathrm{e}-01$ & $1.464709 \mathrm{e}-01$ & $3.843661 \mathrm{e}+00$ & $3.924047 \mathrm{e}+01$ \\
\hline
\end{tabular}

${ }^{\mathrm{a}}$ Read $5.189239 \mathrm{e}-05$ as $5.189239 \times 10^{-5}$.

fraction of the aerosols to form cloud drops. Chuang and Penner [1995] investigated the effect of anthropogenic sulfate on the aerosol size distribution and developed a cloud drop parameterization that was based on the Köhler theory [Ghan et al., 1993] and the chemical processes controlling the formation of anthropogenic sulfate. This parameterization predicts the number concentration of cloud drops nucleated within a GCM grid. The processes of collision/coalescence, mixing and drizzle are not accounted for. Unlike the prescribed aerosol size distribution by Ghan et al. [1993], this parameterization takes into account the anticipated variations in aerosol size distribution due to changes that result from the deposition of anthropogenic sulfate formed in aqueous reactions and the (a) Diameter of cloud drop $=2 \mu \mathrm{m}$

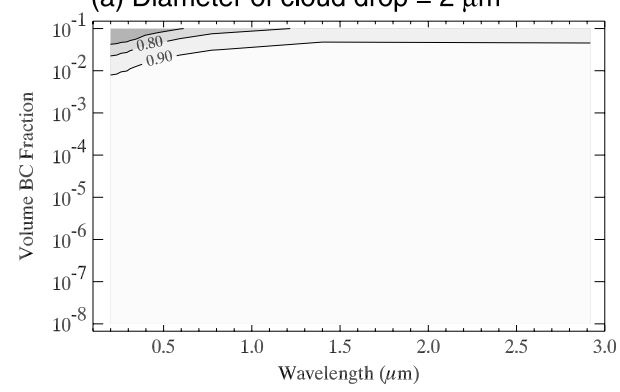

(b) Diameter of cloud drop $=20 \mu \mathrm{m}$

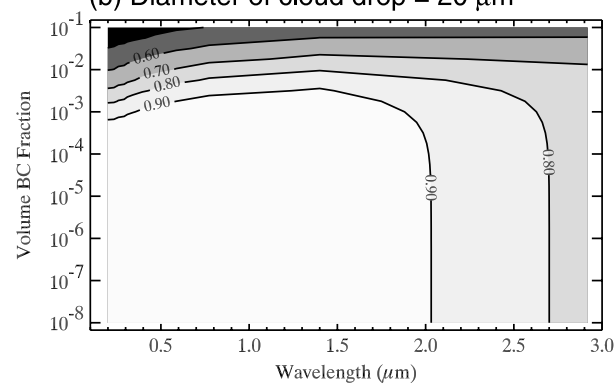

(c) Diameter of cloud drop $=50 \mu \mathrm{m}$

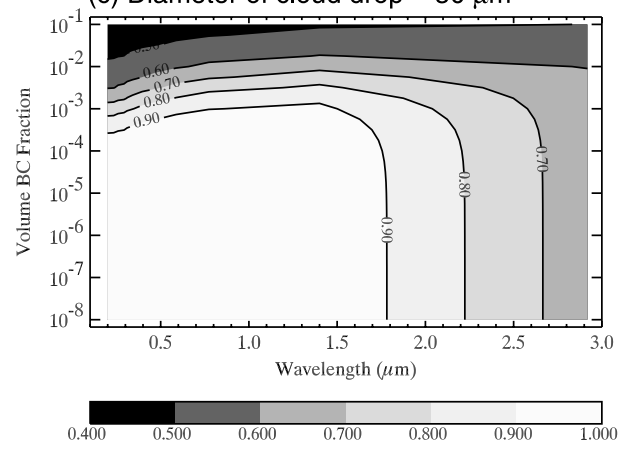

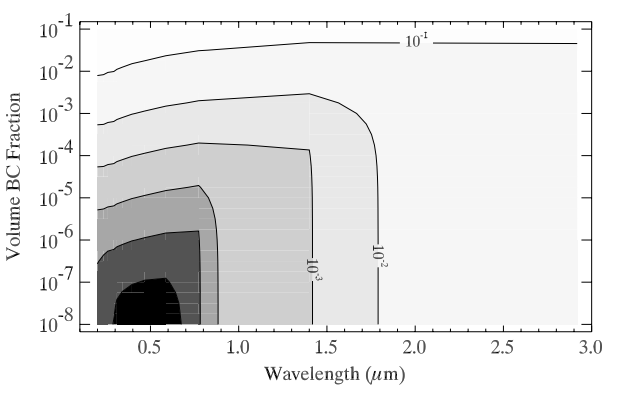
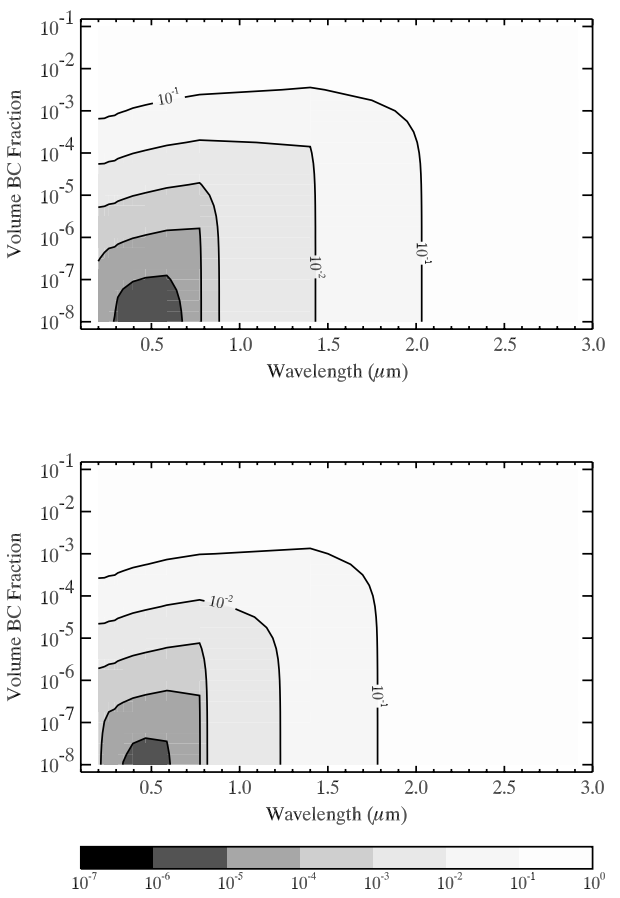

Figure 6. Variations of single scattering albedo (left panel) and co-albedo (right panel) of cloud drops as a function of volume $\mathrm{BC}$ fraction and wavelength. 
Table 4. Size Distribution Parameters for the Preexisting Particles $^{\mathrm{a}}$

\begin{tabular}{lccc}
\hline & $N_{i}^{\mathrm{b}}$ & $D_{i}, \mu \mathrm{m}$ & $\log \sigma_{i}^{\mathrm{c}}$ \\
\hline Continental & 0.548 & 0.025 & 0.25 \\
& 0.450 & 0.060 & 0.30 \\
\multirow{3}{*}{ Marine } & 0.002 & 0.750 & 0.35 \\
& 0.450 & 0.030 & 0.20 \\
& 0.540 & 0.150 & 0.15 \\
& 0.010 & 0.500 & 0.15 \\
\hline
\end{tabular}

${ }^{a}$ Size distribution parameters are adapted from Chuang and Penner [1995].

${ }^{\mathrm{b}} N_{i}$ is normalized by the total number concentration of preexisting particles.

${ }^{\mathrm{c}}$ The $\log$ refers to the base $10 \log$.

condensation of anthropogenic sulfate formed in gas phase reactions. Since anthropogenic sulfate is internally mixed with the preexisting particles, the addition of sulfate does not change the total aerosol number, but the resulting particle distribution grows to larger sizes. This treatment is necessary for particulate sulfate because the timescale for production of $\mathrm{H}_{2} \mathrm{SO}_{4}$ from gas phase $\mathrm{SO}_{2}$ is up to several days. Other aerosol types, such as carbonaceous particles, are formed much more quickly from their gas phase precursors and hence may be assumed to be injected into the global scale model in the aerosol form. We assume an external mixture of preexisting particles with marine sources and a separate mixture of preexisting particles with continental sources. In each case the total particle number concentration is derived from the mass concentrations of natural sulfate, dust, sea salt, and carbonaceous aerosols. With the exception of natural sulfate, the particles that are treated as externally mixed are either emitted as particles initially or form particles rather quickly on the scale of the GCM grid. While this procedure might overestimate the preexisting particle concentrations associated with natural sulfate, the use of an observationally based size distribution tends to obviate against this. Moreover, we have chosen the size distributions for preexisting particles with marine or continental sources such that the simulated aerosol size distribution after the deposition of anthropogenic sulfate is in reasonable agreement with measurements by Hoppel et al. [1990] which were taken off the coast of the United States [see Chuang and Penner, 1995]. While it is true that the assumption of an external mixture could, in general, lead to an overestimate of aerosol number, by using an aerosol size distribution which is applicable to large scales and by accounting for the important processes associated with anthropogenic sulfate which lead to internal mixing on a GCM grid scale, the most important aspects of this problem have been addressed. If they were not, then the processes which lead to internal mixing that we have neglected (i.e., coagulation) would be important on the scale of our GCM prediction, but they are not.

[25] The size distribution of preexisting particles, adapted from Chuang and Penner [1995], is prescribed by the superposition of three lognormal functions with the parameters listed in Table 4. For the purposes of drop nucleation, the mass fraction of soluble material is assumed to be $50 \%$ in the preexisting particles of continental origin and 70\% in the preexisting particles of marine origin, though the parameterization takes into account the variation of solubility with the deposition of anthropogenic sulfate [Chuang and Penner, 1995]. While this is clearly a simplification, since there is no account taken of variations in solubility within regions, the lack of any detailed information on the soluble nature of most of the organics present in the aerosol precludes any detailed treatment of the effect of organics on drop nucleation. Differentiation of the separate effects of dust, sea salt, and natural sulfates is the subject of a new parameterization that is still under development. The detailed microphysical model described by Chuang et al. [1992] is used to develop the parameterization for the interrelationship between anthropogenic sulfate, aerosol number concentration and cloud drop nucleation.

[26] We have evaluated this parameterization by comparing the predicted effective radii of cloud drops with those retrieved from satellites and comparing the drop/aerosol correlation with in-situ measurements [see Chuang et al., 1997]. We also previously examined the consequences of changing the fraction of sulfate formed through aqueous reactions. Increasing the aqueous conversion fraction from $65 \%$ to $85 \%$ can decrease the overall forcing of anthropogenic sulfate by as much as $50 \%$. This parameterization provides a more realistic prediction of drop nucleation process than the empirical methods that were previously used by Jones et al. [1994] and Boucher and Lohmann [1995]. The advantage of this parameterization is its flexibility to varying atmospheric conditions, where the relationship between sulfate mass and drop concentration may be quite different and where the climate system (and updraft velocities) may differ. In particular, this parameterization is also able to capture changes in drop number concentration associated with increasing carbonaceous aerosols derived from both fossil fuel combustion and biomass burning, whereas the empirical formulations only apply to aerosols from industrial regions.

[27] In this study, we applied the cloud drop parameterization used by Chuang et al. [1997] but with a better representation for the number concentration of cloud drops nucleated on aerosols from different origins. This new approach provides a smooth variation of drop concentration with different mixtures of continental and marine aerosols (see Figure 7). The modified parameterization is expressed as

$$
N_{\mathrm{d}}=\frac{w N_{\mathrm{a}, \mathrm{L}}}{w+c_{\mathrm{L}}\left(\mathrm{w}, \gamma, \alpha, N_{\mathrm{a}}^{\mathrm{L}}\right) N_{\mathrm{a}}^{\mathrm{L}}}+\frac{w N_{\mathrm{a}, \mathrm{O}}}{w+c_{\mathrm{O}}\left(\mathrm{w}, \gamma, \alpha, N_{\mathrm{a}}^{\mathrm{O}}\right) N_{\mathrm{a}}^{\mathrm{O}}}
$$

where $N_{\mathrm{d}}\left(\mathrm{cm}^{-3}\right)$ is the drop number concentration, $w(\mathrm{~cm}$ $\left.\mathrm{s}^{-1}\right)$ is the updraft velocity, and $N_{\mathrm{a}, \mathrm{L}}\left(\mathrm{cm}^{-3}\right)$ and $N_{\mathrm{a}, \mathrm{O}}\left(\mathrm{cm}^{-3}\right)$ are number concentrations of submicron particles with continental and marine origins, respectively. $N_{\mathrm{a}, \mathrm{L}}$ and $N_{\mathrm{a}, \mathrm{O}}$ are derived by converting the preexisting continental and marine submicron particle volumes by 0.0524 and 0.085 $\mu \mathrm{m}$, respectively. These volume mean radii are calculated from the prescribed size distributions given in Table 4. To account for the differences in aerosol size distribution from different origins, $N_{\mathrm{a}}^{\mathrm{L}}$ and $N_{\mathrm{a}}^{\mathrm{O}}$ are introduced into equation (8), where $N_{\mathrm{a}}^{\mathrm{L}}$ and $N_{\mathrm{a}}^{\mathrm{O}}$ are the number concentrations derived by converting the total preexisting submicron 
(a) $\operatorname{Mass}\left(\mathrm{SO}_{4}=\right)=0$

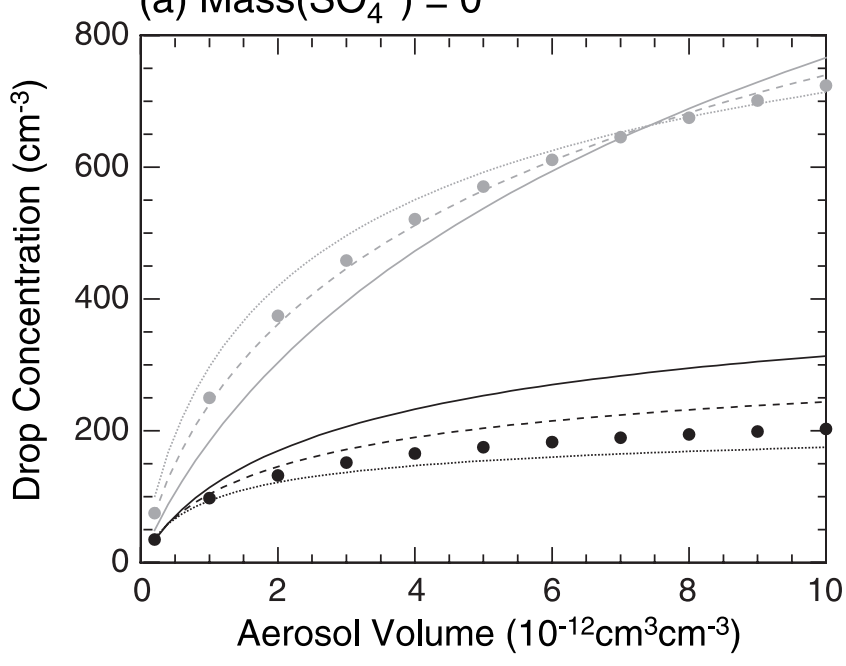

(b) $\operatorname{Mass}\left(\mathrm{SO}_{4}=\right)=5 \mu \mathrm{g} \mathrm{m}^{-3}$

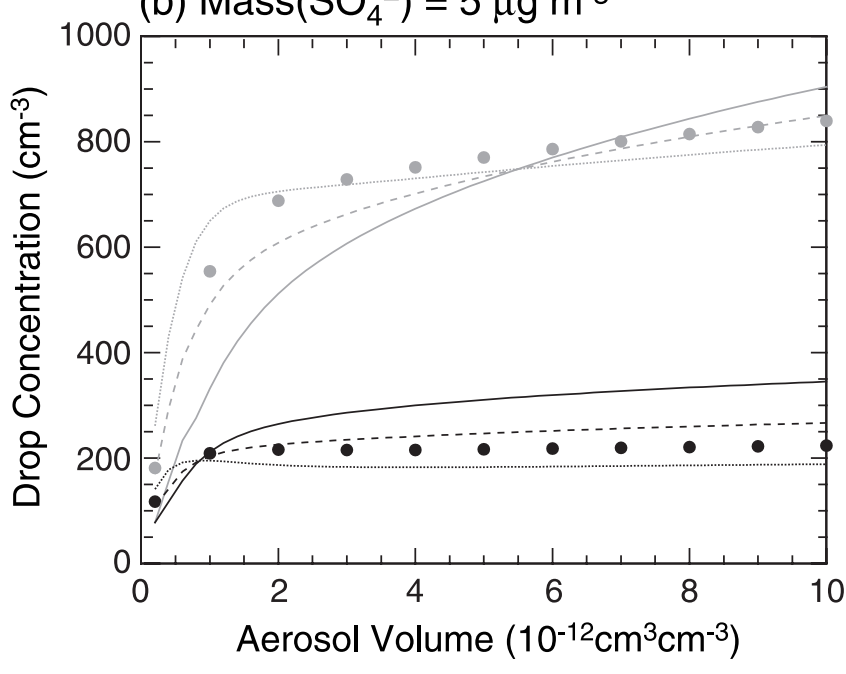

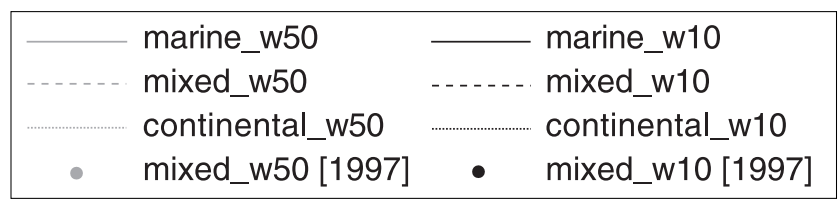

Figure 7. Variations of the predicted drop number concentrations with preexisting submicron particle volume for a given amount of anthropogenic sulfate deposited onto continental, marine, and 50/50 volume mixture of continental and marine aerosols, respectively. w10 and w50 denote an updraft velocity of 10 and $50 \mathrm{~cm} \mathrm{~s}^{-1}$, respectively. Also shown for comparison are the predicted concentrations from Chuang et al. [1997] using a different representation for mixed particles.

particle volume (continental + marine) by 0.0524 and 0.085 $\mu \mathrm{m}$, respectively. $c_{\mathrm{L}}$ and $c_{\mathrm{O}}$ are coefficients given by Chuang et al. [1997].

$$
\begin{array}{ll}
\text { over land } \quad c_{\mathrm{L}}=0.04095+21.587 X_{\mathrm{L}} \\
\text { over ocean } \quad c_{\mathrm{O}}=0.02215-0.1329 X_{\mathrm{O}}+3.0737 X_{\mathrm{O}}^{2}
\end{array}
$$

where

$$
\begin{gathered}
X_{\mathrm{L}}=\frac{1-\frac{0.5+\frac{\gamma}{\alpha^{4}}}{\left(\log N_{\mathrm{a}}^{\mathrm{L}}\right)^{2}} \log w}{\left(\log N_{\mathrm{a}}^{\mathrm{L}}\right)^{5+\frac{\gamma}{\alpha^{3}}}} \log w, \\
X_{\mathrm{O}}=\frac{1-\frac{0.5+0.2 \frac{\gamma}{\alpha^{3}}}{\left(\log N_{\mathrm{a}}^{\mathrm{O}}\right)^{2}} \log w}{\left(\log N_{\mathrm{a}}^{\mathrm{O}}\right)^{2+0.1 \frac{\gamma}{\alpha^{2}}}} \log w
\end{gathered}
$$

$\gamma$ is the ratio of anthropogenic sulfate mass loading (in $\mu \mathrm{g} \mathrm{m} \mathrm{m}^{-3}$ ) to the total aerosol number concentration (in $1000 \mathrm{~cm}^{-3}$ ). $\alpha$ is the ratio of the fraction of anthropogenic sulfate converted by the aqueous pathway to the mean value used previously $(75 \%)$. The coefficient $c$ so derived is for a vertical velocity $w \geq 10 \mathrm{~cm} \mathrm{~s}^{-1}$ and is set to 0 should it become negative for large values of $w, \gamma$, or $N_{\mathrm{d}}$. For $w<10$ $\mathrm{cm} \mathrm{s}^{-1}, N_{\mathrm{d}}$ is approximated by $N_{\mathrm{d}}(w)=N_{\mathrm{d}}(w=10)[2-\log$ $w]^{-2.5}$. The subgrid scale variability of $w$ is prescribed by a normal probability function with the GCM vertical velocity as its mean value and a standard deviation $50 \mathrm{~cm} \mathrm{~s}^{-1}$ [Chuang et al., 1997]. We have previously tested the sensitivity of the model results to this prescription. Our results show that the average magnitude of indirect forcing only various about $6 \%$ corresponding to $50 \%$ variation in standard deviation of subgrid updraft variability function [Chuang et al., 1997].

[28] To illustrate the impact of aerosols with different origins on drop nucleation, we present in Figure 7 the predicted cloud drop number concentrations for a given amount of anthropogenic sulfate deposited onto continental, marine, and 50/50 volume mixture of continental and marine aerosols, respectively. Figure 7 indicates that the percentage increase in drop concentration decreases with the increasing submicron aerosol volume. Because of the smaller mean radius for continental aerosols, the cloud drop concentration would become more easily "saturated" for drops nucleated on continental aerosols.

[29] The cloud drop parameterization so derived is applied to water clouds with temperature $>273^{\circ} \mathrm{K}$. However, water clouds are frequently found in the atmosphere at temperatures below $273^{\circ} \mathrm{K}$ because water readily supercools. The likelihood of clouds consisting entirely of supercooled water drops decreases with decreasing temperature such that at $253^{\circ} \mathrm{K} 95-100 \%$ of clouds contain ice particles [Pruppacher and Klett, 1978]. Therefore, a value of 0.02 (2\%) is chosen to represent the frequency of supercooled water clouds when $T<253^{\circ} \mathrm{K}$. At $273^{\circ} \mathrm{K}>T>253^{\circ} \mathrm{K}$, the cloud drop concentration $N_{\mathrm{d}}$ predicted by equation (8) is scaled by a factor to account for the fraction of water clouds.

$$
N_{\mathrm{d}}^{\prime}(\mathrm{T})=f N_{\mathrm{d}}+(1-f) \frac{T-T_{o}}{T_{1}-T_{o}} N_{\mathrm{d}}
$$

where $f=0.02, T_{1}=273^{\circ} \mathrm{K}$, and $T_{\mathrm{o}}=253^{\circ} \mathrm{K}$. A minimum cloud drop concentration of $0.02 N_{\mathrm{d}}$ is applied at $T<253^{\circ} \mathrm{K}$.

\section{Results}

[30] In this section, we first examine the impact of anthropogenic aerosols on cloud susceptibility. Furthermore, we calculate the first indirect forcing and explore 
Table 5. List of Experiments ${ }^{\mathrm{a}}$

\begin{tabular}{|c|c|c|c|c|c|c|c|}
\hline & \multicolumn{7}{|c|}{ Aerosol Emissions } \\
\hline & \multicolumn{3}{|c|}{ Anthropogenic } & \multicolumn{4}{|c|}{ Natural } \\
\hline & $\mathrm{F}_{-}^{\mathrm{b}} \mathrm{SO}_{2}$ & $\mathrm{~F}^{\mathrm{b}} \mathrm{OM} / \mathrm{BC}^{\mathrm{c}}$ & $\mathrm{B}_{-}^{\mathrm{d}} \mathrm{OM} / \mathrm{BC}^{\mathrm{c}}$ & $\mathrm{N}_{-}^{\mathrm{e}} \mathrm{SO}_{2}$ & $\mathrm{~N}_{-}^{\mathrm{e}} \mathrm{OM}^{\mathrm{c}}$ & $\begin{array}{l}\text { Small Dust }^{\mathrm{f}} \\
(d<2 \mu \mathrm{m})\end{array}$ & $\begin{array}{c}\text { Small Sea Salt }^{\mathrm{f}} \\
(d<2 \mu \mathrm{m})\end{array}$ \\
\hline \multicolumn{8}{|c|}{ Anthropogenic Indirect Forcing Experiments } \\
\hline 1 & 0.00 & 30.54 & 0.00 & $27.89(*)^{g}$ & $16.74(*)$ & $242.96(*)$ & $82.11(*)$ \\
\hline 2 & 0.00 & 0.00 & 45.65 & $27.89(*)$ & $16.74(*)$ & $242.96(*)$ & $82.11(*)$ \\
\hline 3 & 0.00 & 30.54 & 45.65 & $27.89(*)$ & $16.74(*)$ & $242.96(*)$ & $82.11(*)$ \\
\hline 4 & 77.96 & $30.54(*)$ & $45.65(*)$ & $27.89(*)$ & $16.74(*)$ & $242.96(*)$ & $82.11(*)$ \\
\hline 5 & 77.96 & 30.54 & 45.65 & $27.89(*)$ & $16.74\left(^{*}\right)$ & $242.96\left(^{*}\right)$ & $82.11\left(^{*}\right)$ \\
\hline \multicolumn{8}{|c|}{ Sensitivity to BC Absorbing Effect in Clouds } \\
\hline 6 & 0.00 & 30.54 & 45.65 & $27.89(*)$ & $16.74(*)$ & $242.96(*)$ & $82.11(*)$ \\
\hline $7^{\mathrm{h}}$ & 0.00 & 30.54 & 45.65 & $27.89(*)$ & $16.74(*)$ & $242.96(*)$ & $82.11(*)$ \\
\hline \multicolumn{8}{|c|}{ Sensitivity to Natural Aerosol Concentrations } \\
\hline 8 & 77.96 & $30.54(*)$ & $45.65(*)$ & $27.89(*)$ & $8.37(*)$ & $242.96(*)$ & $82.11(*)$ \\
\hline 9 & 0.00 & 30.54 & 45.65 & $27.89(*)$ & $8.37(*)$ & $242.96(*)$ & $82.11(*)$ \\
\hline 10 & 77.96 & $30.54(*)$ & $45.65(*)$ & $27.89(*)$ & $41.85(*)$ & $242.96(*)$ & $82.11(*)$ \\
\hline 11 & 0.00 & 30.54 & 45.65 & $27.89(*)$ & $41.85\left(^{*}\right)$ & $242.96\left(^{*}\right)$ & $82.11(*)$ \\
\hline 12 & 77.96 & $30.54(*)$ & $45.65(*)$ & $27.89(*)$ & $16.74(*)$ & $0.00(*)$ & $82.11(*)$ \\
\hline 13 & 0.00 & 30.54 & 45.65 & $27.89(*)$ & $\left.16.744^{*}\right)$ & $0.00(*)$ & $82.11(*)$ \\
\hline 14 & 77.96 & $30.54(*)$ & $45.65(*)$ & $27.89(*)$ & $16.74(*)$ & $242.96(*)$ & $0.00(*)$ \\
\hline 15 & 0.00 & 30.54 & 45.65 & $27.89(*)$ & $16.74(*)$ & $242.96(*)$ & $0.00(*)$ \\
\hline 16 & 77.96 & $30.54(*)$ & $45.65(*)$ & $27.89(*)$ & $16.74(*)$ & $0.00(*)$ & $0.00(*)$ \\
\hline 17 & 0.00 & 30.54 & 45.65 & $27.89(*)$ & $16.74(*)$ & $0.00(*)$ & $0.00(*)$ \\
\hline
\end{tabular}

${ }^{a}$ Aerosol emissions are in $\mathrm{Tg} \mathrm{yr}^{-1}$ except for $\mathrm{SO}_{2}$ in $\mathrm{Tg} \mathrm{S} \mathrm{yr}^{-1}$. All experiments allow alterations of meteorological fields consistent with currently calculated aerosol concentrations except for Experiments 6 and 7 in which meteorological fields only correspond to natural aerosols.

${ }^{\mathrm{b}}$ Fossil fuel.

${ }^{\mathrm{c}}$ Carbonaceous particles are assumed in the submicron size range $(d<1 \mu \mathrm{m})$.

${ }^{\mathrm{d}}$ Biomass burning.

${ }^{\mathrm{e}}$ Natural.

${ }^{\mathrm{f}}$ Since the amount of submicron particle volume is required for cloud drop parameterization, a ratio of 0.42 and 0.93 should be applied to small dust and sea salt emissions, respectively, to scale the particle volume from $d<2 \mu \mathrm{m}$ to $d<1 \mu \mathrm{m}$. These ratios are derived from Table 4 .

$\mathrm{g}(*)$ Species used in the "offline" radiation calculation.

${ }^{\mathrm{h}}$ Experiment without $\mathrm{BC}$ absorption in clouds.

its sensitivity to black carbon as well as to global aerosol concentrations. Following IPCC [1996], the term "radiative forcing" is defined as changes in the radiative balance of the surface-troposphere system imposed by external factors without involving any feedback from the climate system. We calculate the forcing as difference in solar radiation at top of the atmosphere with and without the fraction of cloud drops nucleated on a prescribed type of anthropogenic aerosols. Thus, an additional "offline" radiation calculation without this aerosol component is performed under identical atmospheric conditions at the time step for full computation of shortwave radiation quantities (every 12 hours). Table 5 lists the experiments performed in this study. In each simulation, a 60-day "spin-up" period (in which the atmos- phere responds to the changes in aerosol concentration) is followed by a full year simulation. Results are presented as either monthly averages or annual averages.

\subsection{Cloud Susceptibility}

[31] The magnitude of the first aerosol indirect effect is associated with cloud frequency as well as a quantity representing the sensitivity of cloud albedo to changes in drop number concentration. This quantity is referred to as cloud susceptibility [Twomey, 1991]. Analysis of satellite measurements demonstrates that marine stratus clouds are likely to be of higher susceptibility than continental clouds because of their lower drop number concentrations [Platnick and Two$m e y, 1994]$. In addition, the column average of cloud fraction

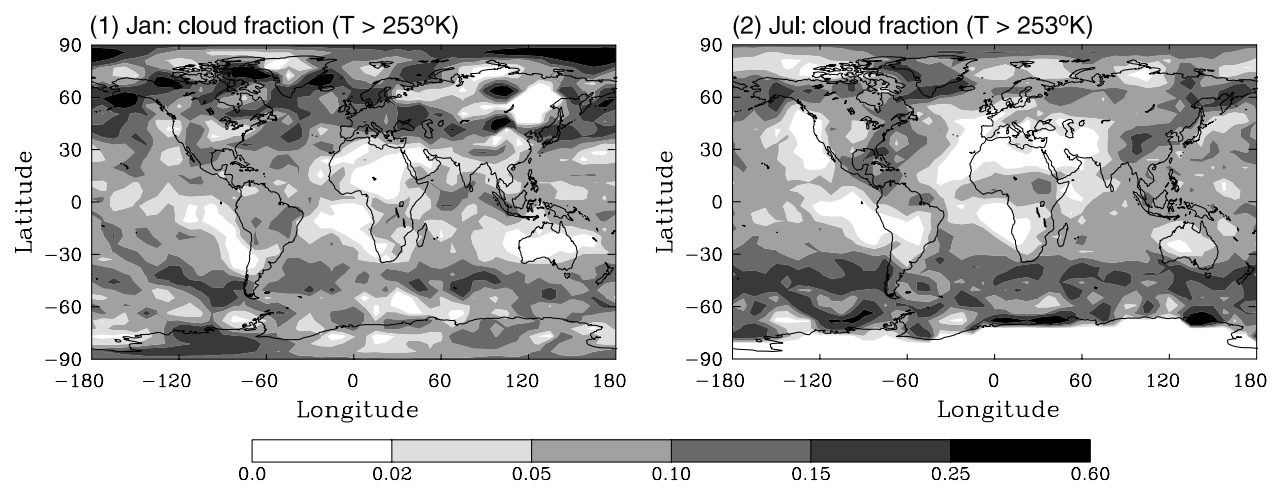

Figure 8. Model simulated column averages of cloud fraction for clouds with $T>253^{\circ} \mathrm{K}$. 

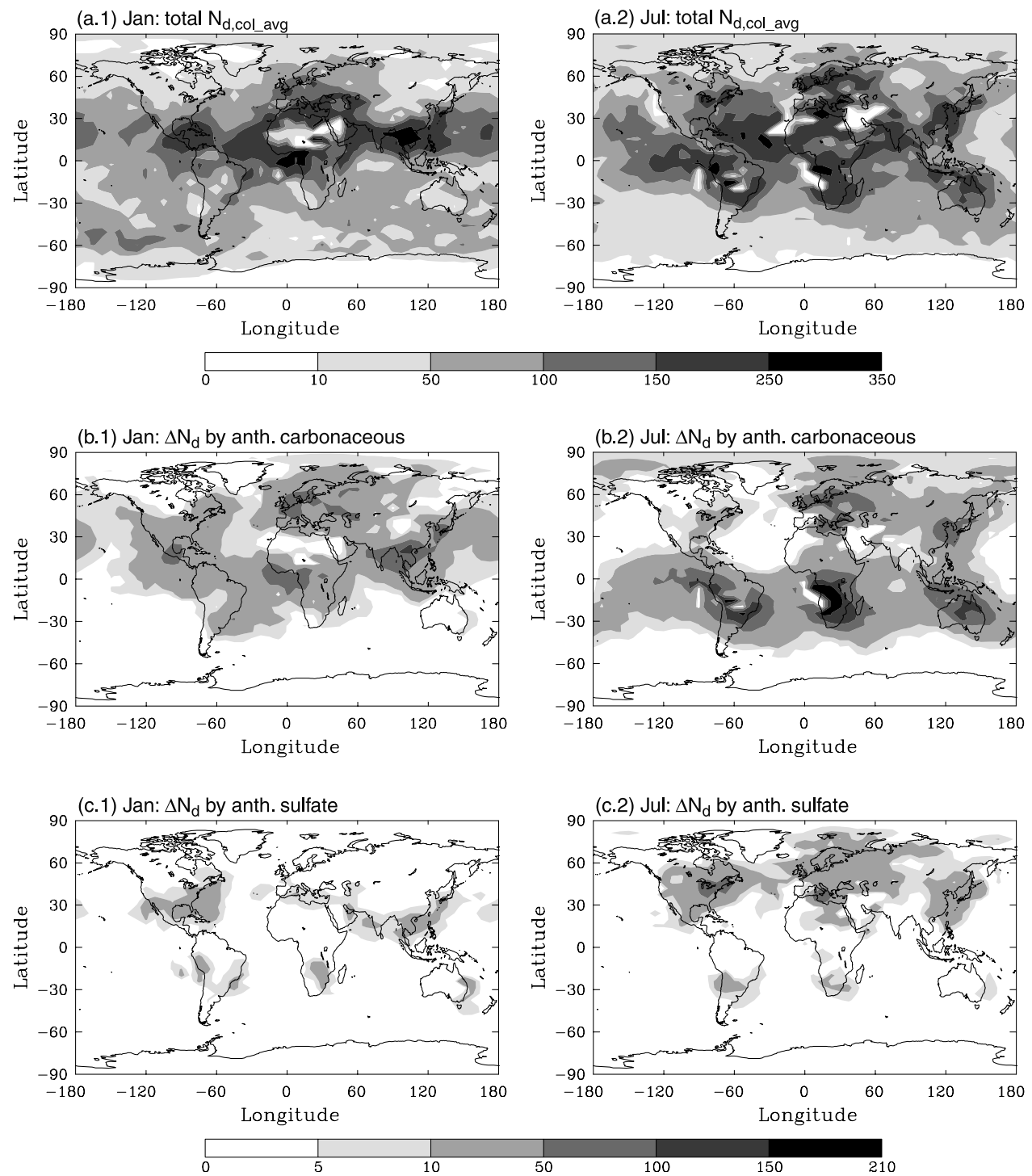

Figure 9. (a) Model simulated column averages of total drop number concentrations $N_{\mathrm{d}, \mathrm{col} \text { avg }}\left(\mathrm{cm}^{-3}\right)$ in clouds with $T>253^{\circ} \mathrm{K}$. (b) Increases of drop concentrations by anthropogenic carbonaceous aerosols. (c) Same as (b) but by anthropogenic sulfate.

calculated for clouds with $T>253^{\circ} \mathrm{K}$ as shown in Figure 8 is, in general, higher over the oceans compared to continental regions. This suggests that the first indirect effect may be more pronounced in the ocean areas.

[32] To examine the cloud susceptibility, we first calculate the column average of drop number concentration $N_{\text {d,col avg }}\left(\mathrm{cm}^{-3}\right)$ corresponding to different aerosol characteristics. Figure 9 presents the simulated monthly averages of total $N_{\text {d,col avg }}$ for clouds with $T>253^{\circ} \mathrm{K}$ as well as the increases of $N_{\mathrm{d} \text {,col avg }}$ by anthropogenic aerosols. These concentrations are those derived from Experiments 4 and 5 listed in Table 5. Figures 9b.1 and 9b.2 show that the increases of drop concentrations by anthropogenic carbonaceous aerosols are over $100 \mathrm{~cm}^{-3}$ in the southeastern China in January and up to $200 \mathrm{~cm}^{-3}$ in Africa in July. The increases in the southeastern China are associated with fossil fuel combustion while the increases in Africa are caused by the biomass burning. Figures 9c.1 and 9c.2 indicate that anthropogenic sulfate also increases the num- ber concentration of cloud drops through modifying the aerosol size distribution, though its associated changes are not as significant as those from carbonaceous aerosols. Increases of drop concentrations by anthropogenic sulfate are up to $30 \mathrm{~cm}^{-3}$ for January and $90 \mathrm{~cm}^{-3}$ for July in regions off the east coast of Australia and the east of the United States, respectively.

[33] According to Twomey [1977a], the optical thickness of a cloud with narrow drop size distribution and constant liquid water content can be approximated by

$$
\tau=h\left[\frac{9 \pi w_{\mathrm{L}, \text { col_avg }}^{2} N_{\mathrm{d}, \mathrm{col} \_a v g}}{2 \rho^{2}}\right]^{\frac{1}{3}}
$$

where $h$ is the cloud depth calculated from the total thickness of model layers where clouds with $T>253^{\circ} \mathrm{K}$ are present, $\rho$ is the density of liquid water, and $w_{\mathrm{L}, \mathrm{col} \text { avg }}$ is the column average of cloud liquid water content. Calculations of cloud 

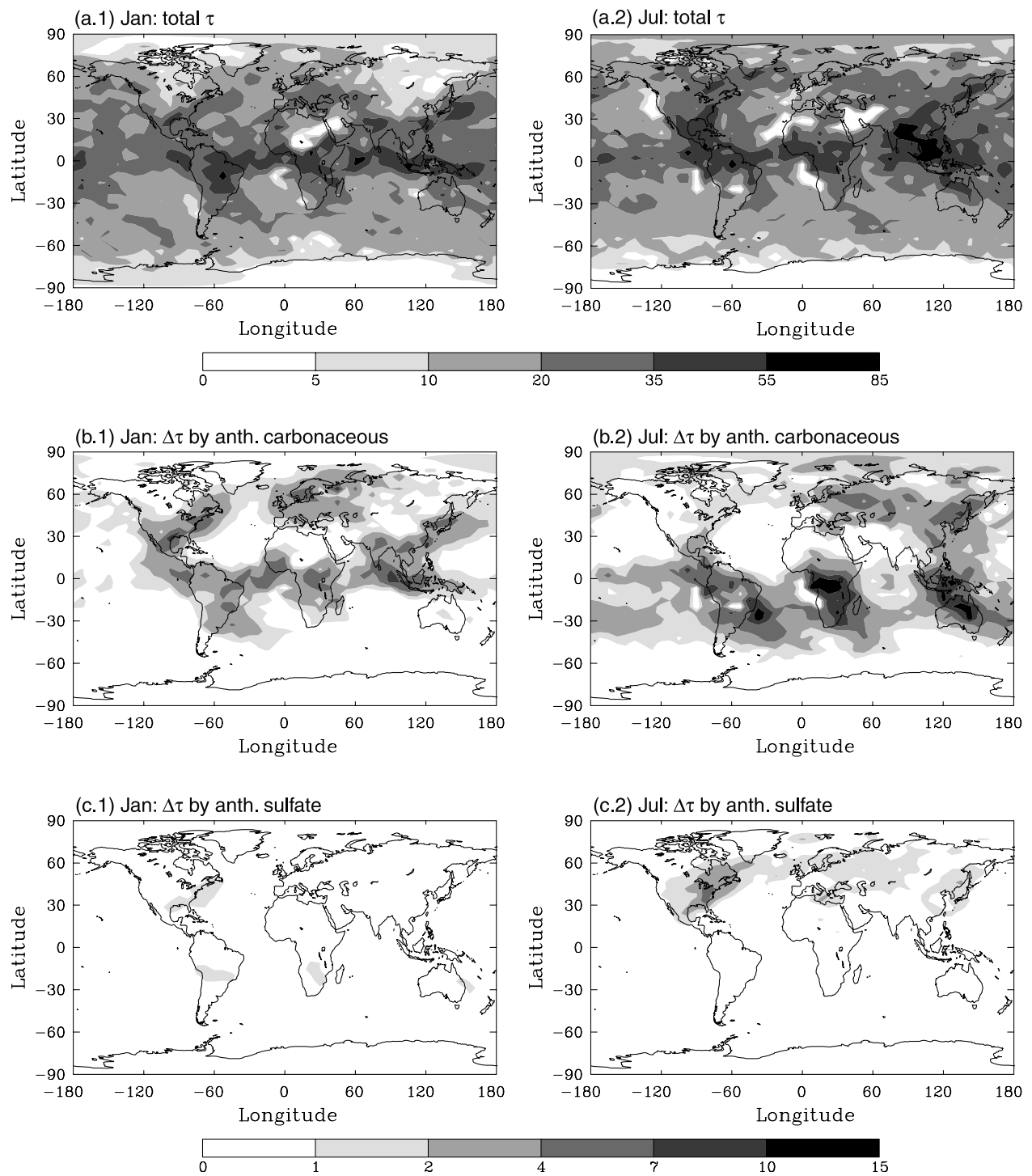

Figure 10. (a) Model simulated cloud optical thickness $\tau$ for clouds with $T>253^{\circ} \mathrm{K}$. (b) Variations of $\tau$ associated with anthropogenic carbonaceous aerosols. (c) Same as (b) but for anthropogenic sulfate.

optical thickness are presented in Figure 10. Our simulations show a well-defined zonal band with larger cloud optical thickness located north of the equator in July and slightly moving southward in January. The presence of this zonal band is consistent with the location of intertropical convergence zone (ITCZ). Our simulations also indicate that the increases of cloud optical thickness by anthropogenic aerosols are more pronounced in July. Changes in the Northern Hemisphere are mainly associated with industrial sulfate and carbonaceous aerosols while changes in the Southern Hemisphere are associated with biomass aerosols.

[34] The increases of cloud optical thickness by anthropogenic aerosols increase the reflectance (albedo) of clouds, though the absorption of black carbon acts to darken the clouds. However, the effect of black carbon on cloud albedo can only be seen in the brightest clouds $(\tau>100)$ [Twomey, 1977b]. This is in agreement with AVHRR study by Kaufman and Nakajima [1993], which showed a reduction in the visible albedo for initially bright clouds (from 0.71 to 0.67 ) in the presence of dense smoke in the Brazilian Amazon basin. For both mathematical and physical simplification, in our calculation of cloud susceptibility, a nonabsorbing, horizontally homogeneous cloud is assumed and the cloud albedo is parameterized in terms of cloud optical thickness [Lacis and Hansen, 1974]

$$
\alpha_{c}=\frac{\tau}{7.7+\tau}
$$

Furthermore, the cloud susceptibility may be expressed by

$$
S=\frac{\partial \alpha_{\mathrm{c}}}{\partial N_{\mathrm{d}, \mathrm{col} \_ \text {avg }}}=\frac{\alpha_{\mathrm{c}}\left(1-\alpha_{\mathrm{c}}\right)}{3 N_{\mathrm{d}, \mathrm{col} \_a v g}}
$$

as cloud liquid water content remains constant. Figure 11 presents our calculated cloud susceptibility for January and July together with the decreases of cloud susceptibility by anthropogenic aerosols. The values of cloud susceptibility vary by about two orders of magnitude with a maximum over the Antarctica region. The presence of anthropogenic 

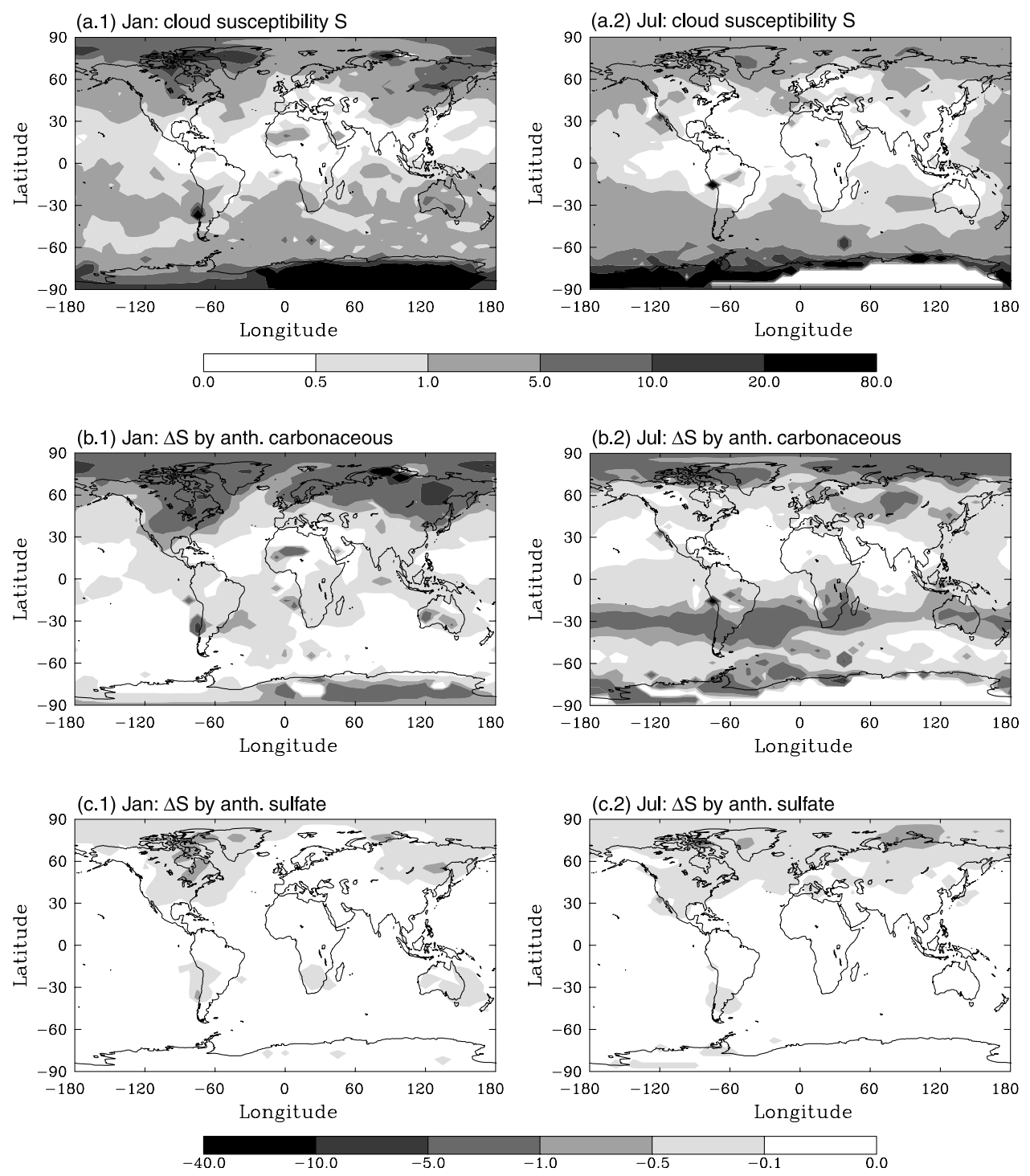

Figure 11. (a) Model calculated cloud susceptibility $S\left(\times 10^{-3} \mathrm{~cm}^{3}\right)$ for clouds with $T>253^{\circ} \mathrm{K}$. (b) Changes of $S$ associated with anthropogenic carbonaceous aerosols. (c) Same as (b) but for anthropogenic sulfate.

aerosols reduces the cloud susceptibility by a value up to $40 \times 10^{-3} \mathrm{~cm}^{3}$. Our simulations show that the cloud susceptibility is larger over remote ocean areas than over continents and larger in the Southern Hemisphere than in the northern hemisphere. Figures $11 \mathrm{~b}$ and $11 \mathrm{c}$ also indicate that the presence of industrial aerosols has significantly reduced cloud susceptibility in the Northern Hemisphere in January, and biomass aerosols have reduced susceptibility in the Southern Hemisphere in July.

\subsection{Comparison of Cloud Susceptibility to Satellite Measurements}

[35] Our calculated cloud susceptibilities are consistent to those retrieved from the advanced very high resolution radiometer (AVHRR) measurements in a single cloud event. The retrieved magnitude of susceptibility ranges from $0.2 \times$ $10^{-3}$ to $0.8 \times 10^{-3} \mathrm{~cm}^{3}$ in marine stratus off the coast of Namibia and South Africa (4 January and 19 April, 1989) and from $0.3 \times 10^{-3}$ to $20 \times 10^{-3} \mathrm{~cm}^{3}$ in marine stratus/ stratocumulus off the coast of southern California (30 June and 10 July, 1987) [Platnick and Twomey, 1994]. Our model results for the same areas and specific time periods are $0.7 \times$ $10^{-3}$ to $1.9 \times 10^{-3} \mathrm{~cm}^{3}$ and $0.5 \times 10^{-3}$ to $16 \times 10^{-3} \mathrm{~cm}^{3}$, respectively.

[36] Additionally, we calculate the susceptibility for warm clouds $\left(T>273^{\circ} \mathrm{K}\right)$ (shown in Figure 12a) and compare the simulated distributions with those derived from the monthly averages of satellite-retrieved cloud optical thickness $\tau$ and effective drop radius $r_{\mathrm{e}}$. These data were retrieved from 1989 to 1991 AVHRR measurements using the algorithm developed by Kawamoto et al. [2001]. The liquid water path is calculated from the relation $w_{\text {path }}=(2 / 3) \rho \tau r_{\mathrm{e}}$. The column drop number concentration, under assumption of a vertically homogeneous drop profile, is estimated from $N_{\mathrm{d}, \mathrm{col}}\left(\mathrm{cm}^{-2}\right)=\tau r_{\mathrm{e}} /\left(2 \pi r_{\mathrm{v}}^{3}\right)$, where $r_{\mathrm{v}}$ is the volume mean radius of the drop size distribution. Here, we assume a lognormal drop size distribution (in natural logarithm) with a standard deviation $\sigma=1.4$ and a mode radius $r_{\mathrm{o}}$ that is 

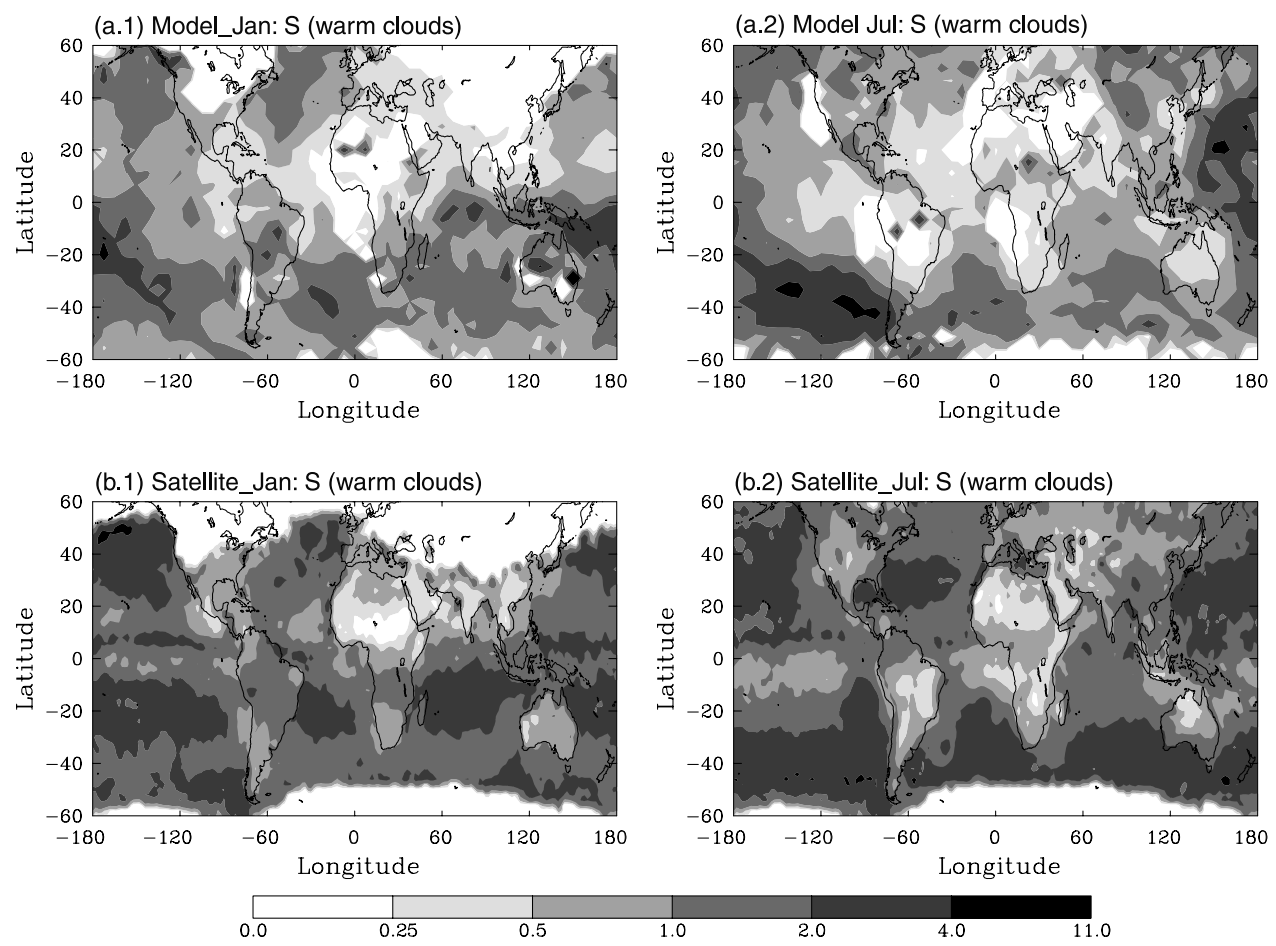

Figure 12. Comparison of the model calculated cloud susceptibility $\left(\times 10^{-3} \mathrm{~cm}^{3}\right)$ for warm clouds $(T>$ $273^{\circ} \mathrm{K}$ ) with those inferred from satellite measurements.

determined by $r_{\mathrm{o}}=r_{\mathrm{e}} \exp \left[-2.5(\ln \sigma)^{2}\right]$. For a vertically homogeneous drop profile, $N_{\mathrm{d}, \mathrm{col}}=N_{\mathrm{d}, \mathrm{s}} h_{\mathrm{s}}$ and $w_{\text {path }}=w_{\mathrm{L}} h_{\mathrm{s}}$, where $N_{\mathrm{d}, \mathrm{s}}$ and $h_{\mathrm{s}}$ are the satellite-retrieved drop concentration and cloud thickness for warm clouds, respectively. A typical value of liquid water content $w_{\mathrm{L}}=0.30 \mathrm{~g} \mathrm{~m}^{-3}$ is used to estimate $h_{\mathrm{s}}$ and then obtain the satellite-retrieved $N_{\mathrm{d}, \mathrm{s}}$. Susceptibility calculations, using equation (13) with the satellite-retrieved data, are shown in Figure $12 \mathrm{~b}$.

[37] General features of the satellite-derived cloud susceptibility are similar to those of the model, though the magnitude is higher by about a factor of 2 in most of the regions except over the South Pacific Ocean in July. The use of a cloud drop number parameterization that does not account for the processes of collision/coalescence and mixing may contribute to the discrepancy. Such simplification results in an overprediction of drop number concentrations for cloud scales. However, the coarse vertical resolution of CCM1 with only 12 vertical levels lowers the predicted drop concentrations [Ghan et al., 1997]. These two factors, compensating for each other, are the major uncertainty contributing to the model-predicted cloud susceptibility. The discrepancy may also be caused by the uncertainty in the prescribed drop size distribution where the satellite-retrieved $N_{\mathrm{d}, \mathrm{col}}$ varies with the assumed value of $\sigma$. For $r_{\mathrm{e}}=10 \mu \mathrm{m}$, the retrieved $N_{\mathrm{d}, \mathrm{col}}$ would be $27 \%$ lower if $\sigma$ decreases from 1.4 to 1.1 and would be higher by a factor of 3 if $\sigma=2.0$. There are further uncertainties associated with the prescribed liquid water content and the retrieved cloud top temperature. An increase in $w_{\mathrm{L}}$ from $0.30 \mathrm{~g} \mathrm{~m}^{-3}$ to $0.35 \mathrm{~g} \mathrm{~m}^{-3}$ would reduce the satellite-derived susceptibility by $17 \%$. A temperature error of $2.5^{\circ} \mathrm{K}$ could cause an error in retrieved $r_{\mathrm{e}}$ of about 7\% [Kawamoto et al., 2001] which would lead to a comparable uncertainty in susceptibility. Further investigation is needed to give an overall uncertainty of the estimated cloud susceptibility derived from both the model and satellite measurements.

\subsection{First Indirect Forcing by Anthropogenic Aerosols}

[38] The first indirect forcing from each individual source is calculated in the first set of experiments (Experiments 1-5). Figure 13a presents the global distributions of the simulated forcing by anthropogenic carbonaceous aerosols for January and July. In general, the forcing in July is stronger than that in January, and yields a global average of -1.59 and $-1.05 \mathrm{~W} \mathrm{~m}^{-2}$, respectively. The maximum value is about $-7.7 \mathrm{~W} \mathrm{~m}^{-2}$ along the west coast of Mexico in January and $-8.6 \mathrm{~W} \mathrm{~m}^{-2}$ along the east coast of Brazil in July. Anthropogenic carbonaceous aerosols together with natural particles are treated as an external mixture in the cloud drop parameterization and lead to a global annual average of the first indirect forcing in the amount of $-1.51 \mathrm{~W} \mathrm{~m}^{-2}$. This value is much lower than our previous study $(-2.5$ to $-4.5 \mathrm{~W} \mathrm{~m}^{-2}$, see Penner et al. [1996]) in which part of natural emissions were absent. Figure 13b shows the first indirect forcing by anthropogenic sulfate deposited onto preexisting particles derived from natural emissions and anthropogenic carbonaceous sources. The maximum forcing is about $-1.6 \mathrm{~W} \mathrm{~m}^{-2}$ in January and $-5.1 \mathrm{~W} \mathrm{~m}^{-2}$ along the east coast of the United States. While the forcing pattern is similar to that calculated previously by Chuang et al. [1997], the forcing magnitude is considerably smaller and leads to a global annual average of $-0.30 \mathrm{~W} \mathrm{~m}^{-2}$. Current calculations use the model-generated aqueous sulfate production rate. This rate is approximately $88 \%$ of the total sulfate source strength. These simulations may, therefore, be compared to the previously calculated forcing of $-0.41 \mathrm{~W} \mathrm{~m}^{-2}$ for a case of prescribed $85 \%$ sulfate production through the aqueous pathway [Chuang et al., 1997]. The present values are 

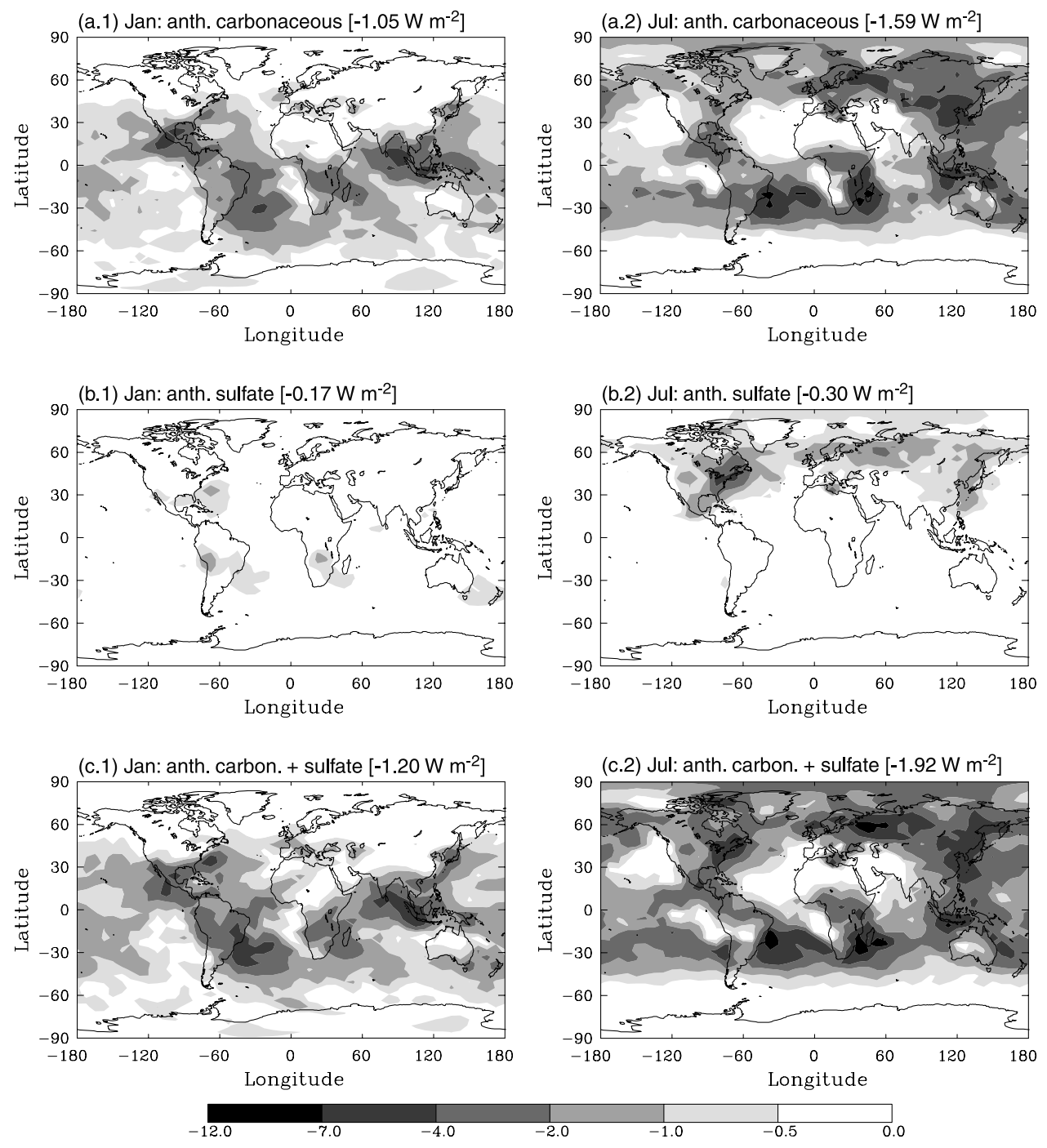

Figure 13. Monthly averages of the simulated first indirect forcing ( $\left.\mathrm{W} \mathrm{m}^{-2}\right)$ by (a) anthropogenic carbonaceous aerosols, (b) deposition of anthropogenic sulfate onto preexisting particles, and (c) total anthropogenic aerosols. Value shown in bracket is the global average.

smaller both because of the larger source strength for natural organic aerosols and because of the presence of sea salt and dust. Distributions of the first indirect forcing by total anthropogenic aerosols are shown in Figure 13c.

[39] Our simulations indicate that the global average of the first indirect forcing by total anthropogenic aerosols is largest in April-June associated with tropical biomass burning of savanna and forested areas. The magnitude of forcing varies seasonally from $-1.2 \mathrm{~W} \mathrm{~m}^{-2}$ in January to $-2.4 \mathrm{~W} \mathrm{~m}^{-2}$ in May and yields a global annual average of $-1.85 \mathrm{~W} \mathrm{~m}^{-2}$. The magnitudes of the simulated forcing by different anthropogenic aerosol components and sources are listed in Table 6. We note that because of the nonlinear relationship between drop number and aerosol number concentrations, the total forcing does not equal the sum of the forcing from each individual source.

Table 6. Model Simulated First Aerosol Indirect Forcing ${ }^{\mathrm{a}}$

\begin{tabular}{|c|c|c|c|c|c|c|c|c|c|c|c|c|c|c|c|}
\hline & \multicolumn{9}{|c|}{ Carbonaceous $\left(\mathrm{nOM}=16.74 \mathrm{Tg} \mathrm{yr}^{-1}\right)$} & \multirow{2}{*}{\multicolumn{3}{|c|}{ Sulfate }} & \multicolumn{3}{|c|}{ Carbonaceous + Sulfate } \\
\hline & \multicolumn{3}{|c|}{ Fossil Fuel } & \multicolumn{3}{|c|}{ Biomass } & \multicolumn{3}{|c|}{ Total } & & & & & & \\
\hline & Jan. & July & Ann & Jan. & July & Ann & Jan. & July & Ann & Jan. & July & Ann & Jan. & July & Ann \\
\hline Global & -0.22 & -0.55 & -0.52 & -0.88 & -1.17 & -1.16 & -1.05 & -1.59 & -1.51 & -0.17 & -0.30 & -0.30 & -1.20 & -1.92 & -1.85 \\
\hline $\mathrm{NH}$ & -0.32 & -0.99 & -0.92 & -0.71 & -0.71 & -0.98 & -0.93 & -1.53 & -1.64 & -0.15 & -0.52 & -0.45 & -1.07 & -1.98 & -2.12 \\
\hline Land & -0.19 & -1.28 & -1.02 & -0.37 & -0.57 & -0.69 & -0.47 & -1.80 & -1.47 & -0.07 & -0.68 & -0.43 & -0.61 & -2.28 & -1.85 \\
\hline Ocean & -0.40 & -0.81 & -0.85 & -0.92 & -0.81 & -1.17 & -1.24 & -1.36 & -1.75 & -0.20 & -0.42 & -0.46 & -1.36 & -1.79 & -2.29 \\
\hline SH & -0.12 & -1.03 & -0.11 & -1.05 & -1.63 & -1.33 & -1.17 & -1.64 & -1.38 & -0.19 & -0.07 & -0.15 & -1.34 & -1.86 & -1.57 \\
\hline Land & -0.10 & -0.07 & -0.10 & -1.14 & -1.09 & -1.32 & -1.26 & -1.53 & -1.35 & -0.27 & -0.06 & -0.20 & -1.51 & -1.47 & -1.56 \\
\hline Ocean & -0.12 & -0.11 & -0.12 & -1.03 & -1.76 & -1.33 & -1.15 & -1.67 & -1.39 & -0.17 & -0.07 & -0.14 & -1.30 & -1.95 & -1.57 \\
\hline
\end{tabular}

${ }^{\mathrm{a}}$ Forcing is in $\mathrm{W} \mathrm{m}^{-2}$. NH, Northern Hemisphere; SH, Southern Hemisphere. 
(a) No absorption by BC in clouds [-1.58 $\left.\mathrm{W} \mathrm{m}^{-2}\right]$

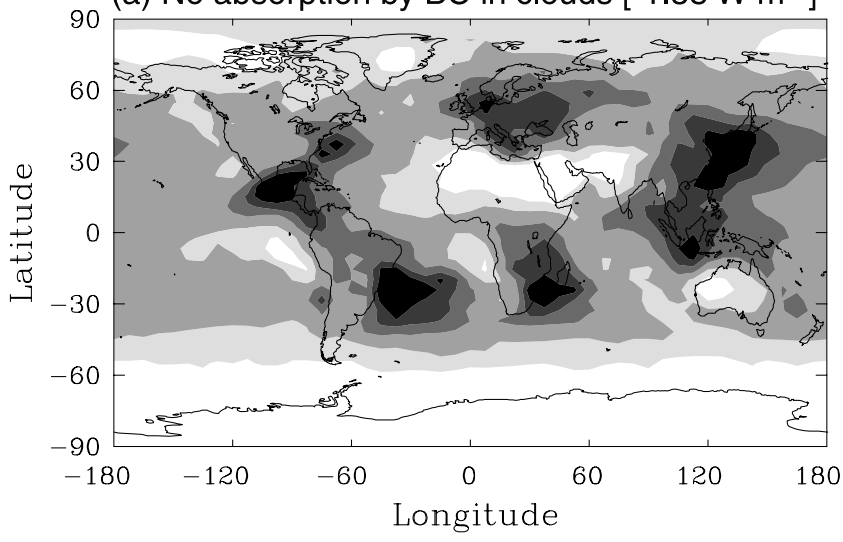

(b) With absorption by $\mathrm{BC}$ in clouds $\left[-1.51 \mathrm{~W} \mathrm{~m}^{-2}\right]$
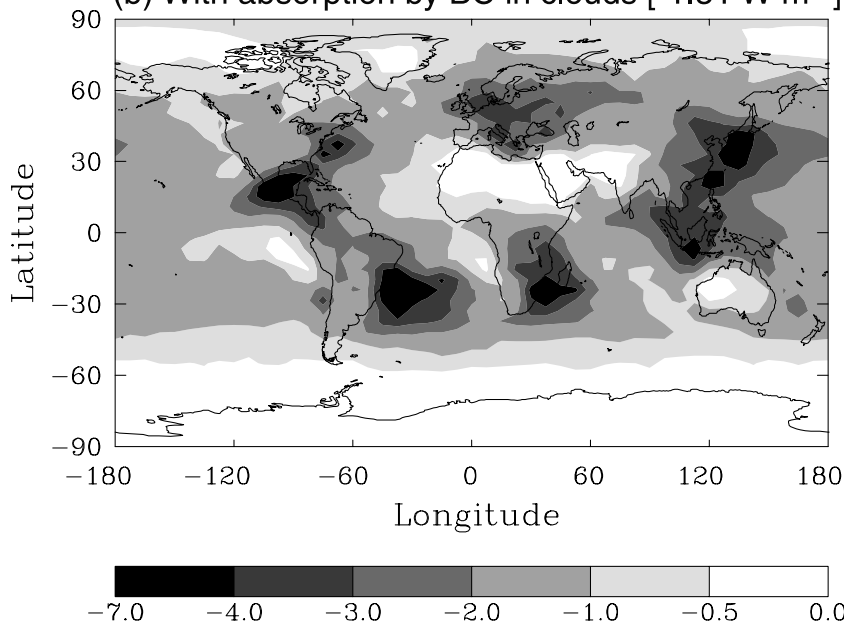

(c) Change between (a) and (b) $\left[0.07 \mathrm{~W} \mathrm{~m}^{-2}\right]$
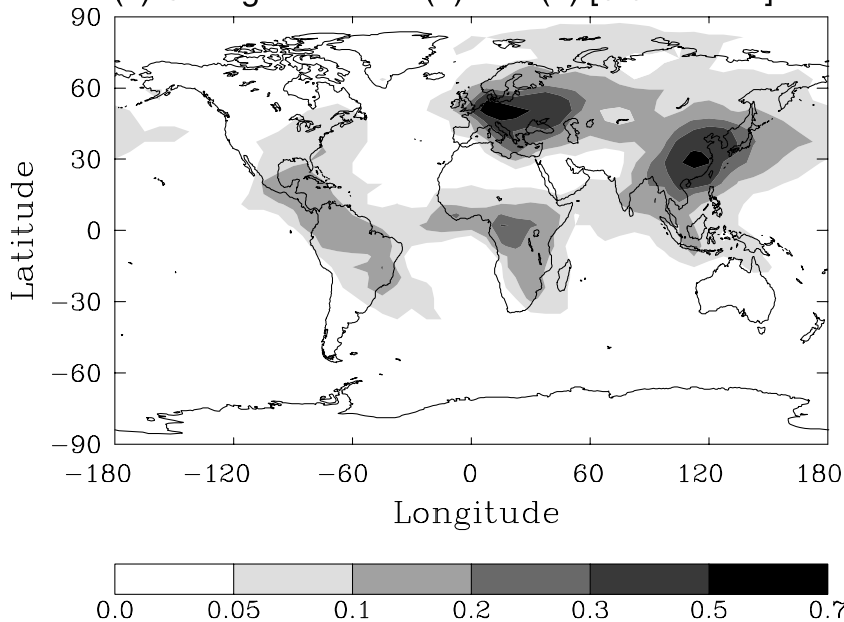

Figure 14. Annual average of the simulated first indirect forcing $\left(\mathrm{W} \mathrm{m}^{-2}\right)$ by anthropogenic carbonaceous aerosols (a) without absorption by $\mathrm{BC}$ in clouds, and (b) with absorption by $\mathrm{BC}$ in clouds. (c) Increases in the magnitude of forcing if the effect of $\mathrm{BC}$ absorption in clouds is not taken into account. Value shown in bracket is the global average.

\subsection{Sensitivity of the First Indirect Forcing to Black Carbon and Natural Aerosols}

\subsubsection{Sensitivity to Black Carbon Absorption} in Clouds

[40] Here, we present model results from Experiments 6 and 7 to examine the effect of black carbon on absorption by clouds. Figures $14 \mathrm{a}$ and $14 \mathrm{~b}$ show the annual average of the simulated first indirect forcing by anthropogenic carbonaceous aerosols without and with the absorption by $\mathrm{BC}$ in clouds, respectively. Figure 14c shows the increases in the magnitude of forcing if this effect is not taken into account. We note that including this absorption has only a minor effect on the global forcing $\left(-1.51\right.$ versus $-1.58 \mathrm{~W} \mathrm{~m}^{-2}$ with and without the effect of $\mathrm{BC}$ absorption in clouds, respectively). There is, however, a significant impact in the simulated forcing over Europe and the eastern China. A simulation that does not include the effect of $\mathrm{BC}$ absorption in clouds could overestimate the first indirect forcing from anthropogenic carbonaceous aerosols by up to $15-25 \%$ in regions where black carbon emissions are pronounced.

\subsubsection{Sensitivity to Natural Aerosols}

[41] The magnitude of the first aerosol indirect forcing is strongly dependent on the existing cloud susceptibility, and therefore, is related to the existing concentrations of natural aerosols. Here, we not only calculate the sensitivity of simulated forcing to the uncertainty in natural organic emissions but also examine the importance of sea salt and dust in the forcing assessment.

[42] To explore the first issue, we perform Experiments 811 with a source strength of natural organic emissions between 8 and $42 \mathrm{Tg} \mathrm{yr}^{-1}$. For carbonaceous forcing, the simulated global annual average with natural organic emissions of $8.37 \mathrm{Tg} \mathrm{yr}^{-1}$ would increase by $11 \%$ from the baseline simulation where natural organic emissions are 16.7 $\mathrm{Tg} \mathrm{yr}^{-1}$ (see Table 7). If natural organic emissions are $41.8 \mathrm{Tg} \mathrm{yr}^{-1}$, the forcing decreases by $16 \%$. The percentage increase or decrease in the forcing is about the same magnitude in both hemispheres but is higher over the continents. For sulfate forcing, the global annual average varies by about $3-13 \%$ corresponding to the uncertainty in natural organic emissions.

[43] Our simulations from Experiments 12-17 demonstrate that natural emissions from dust and sea salt play an important role in the assessment of the first indirect forcing by anthropogenic aerosols (see Table 7). Without including dust as part of the background particles, the simulated forcing increases significantly in the Northern Hemisphere. The global annual average of the first indirect forcing by anthropogenic carbonaceous and sulfate particles would be overestimated by about $87 \%$ and $30 \%$, respectively. The omission of sea salt, on the other hand, increases the forcing more significantly in the Southern Hemisphere. The forcing would be overestimated by about $37 \%$ and $20 \%$ for anthropogenic carbonaceous and sulfate aerosols, respectively. Without dust and sea salt, the magnitude of the simulated first indirect forcing is close to that reported in our previous study [Penner et al., 1996].

\section{Summary and Discussion}

[44] We use the fully coupled climate/chemistry (CCM1/ GRANTOUR) models together with specified emissions 
Table 7. Sensitivity of the Calculated First Indirect Forcing to Global Aerosol Concentrations ${ }^{\mathrm{a}}$

\begin{tabular}{|c|c|c|c|c|c|c|c|c|c|c|}
\hline & \multicolumn{4}{|c|}{$\mathrm{nOM}$} & \multicolumn{6}{|c|}{$\mathrm{nOM}=16.74 \mathrm{Tg} \mathrm{yr}^{-1}$} \\
\hline & \multicolumn{2}{|c|}{$8.37 \mathrm{Tg} \mathrm{yr}^{-1}$} & \multicolumn{2}{|c|}{$41.85 \mathrm{Tg} \mathrm{yr}^{-1}$} & \multicolumn{2}{|c|}{ No Dust } & \multicolumn{2}{|c|}{ No Sea Salt } & \multicolumn{2}{|c|}{ No Dust and Sea Salt } \\
\hline & $\mathrm{SO}_{4}$ & $\mathrm{OM} / \mathrm{BC}$ & $\mathrm{SO}_{4}$ & $\mathrm{OM} / \mathrm{BC}$ & $\mathrm{SO}_{4}$ & $\mathrm{OM} / \mathrm{BC}$ & $\mathrm{SO}_{4}$ & $\mathrm{OM} / \mathrm{BC}$ & $\mathrm{SO}_{4}$ & $\mathrm{OM} / \mathrm{BC}$ \\
\hline Global & -0.31 & -1.67 & -0.26 & -1.27 & -0.39 & -2.82 & -0.36 & -2.07 & -0.51 & -4.06 \\
\hline $\mathrm{NH}$ & -0.46 & -1.82 & -0.39 & -1.38 & -0.61 & -3.68 & -0.50 & -1.90 & -0.76 & -4.76 \\
\hline Land & -0.47 & -1.65 & -0.36 & -1.14 & -0.60 & -3.48 & -0.46 & -1.48 & -0.66 & -3.83 \\
\hline Ocean & -0.46 & -1.93 & -0.41 & -1.53 & -0.61 & -3.80 & -0.53 & -2.17 & -0.83 & -5.35 \\
\hline SH & -0.16 & -1.53 & -0.13 & -1.17 & -0.16 & -1.96 & -0.23 & -2.24 & -0.26 & -3.37 \\
\hline Land & -0.21 & -1.62 & -0.15 & -0.99 & -0.21 & -2.07 & -0.24 & -1.54 & -0.27 & -2.56 \\
\hline Ocean & -0.14 & -1.50 & -0.13 & -1.21 & -0.15 & -1.93 & -0.23 & -2.40 & -0.26 & -3.55 \\
\hline
\end{tabular}

${ }^{\mathrm{a}}$ Forcing is in $\mathrm{W} \mathrm{m}^{-2}$. NH, Northern Hemisphere; SH, Southern Hemisphere.

inventories to model global aerosol concentrations. The simulated surface aerosol concentrations are similar to those presented previously but are compared to additional new measurements here to further evaluate the adequacy of the model. A modified cloud drop parameterization has been applied to calculate the concentrations of cloud drops nucleated on different aerosol components. We find that the increases of drop number concentrations can be up to $200 \mathrm{~cm}^{-3}$ due to anthropogenic carbonaceous aerosols and up to $30-90 \mathrm{~cm}^{-3}$ due to the change of aerosol size distribution associated with anthropogenic sulfate. The presence of anthropogenic aerosols would reduce the cloud susceptibility by a value of up to $40 \times 10^{-3} \mathrm{~cm}^{3}$. Our simulations are consistent with the analysis of satelliteretrieved cloud susceptibility and demonstrate that marine stratus clouds are more sensitive to changes in drop concentration than continental clouds [Platnick and Twomey, 1994]. We note that our cloud drop parameterization does not include the impact of drop spectral broadening on the cloud susceptibility. The study by Feingold et al. [1997] demonstrates that equation (11) would overestimate the cloud optical thickness when drop spectra broaden through collection. The dependence of cloud susceptibility on drop number concentration is larger for clouds with an active collection process. In spite of this shortcoming in the cloud drop parameterization, our simulations provide a global understanding of the effects of anthropogenic aerosols on the susceptibility of water clouds.

[45] We also estimate the first indirect forcing by anthropogenic aerosols. The forcing pattern is determined by the magnitude of cloud susceptibility, cloud frequency as well as the incoming solar radiation. As shown in Table 6, we find that biomass aerosols acting as CCN would cool the Earth/ atmosphere system by about $-1.16 \mathrm{~W} \mathrm{~m}^{-2}$, while carbonaceous aerosols from fossil fuel combustion acting alone may cool the system by about $-0.52 \mathrm{~W} \mathrm{~m}^{-2}$. However, because of the nonlinear nature of cloud drop nucleation, the independently computed forcings by carbonaceous aerosols derived from different anthropogenic sources do not add linearly. The total first indirect forcing by anthropogenic carbonaceous aerosols is estimated to be about $-1.51 \mathrm{~W}$ $\mathrm{m}^{-2}$. Variations in the natural organic aerosol emissions from 8.37 to $41.85 \mathrm{Tg} \mathrm{yr}^{-1}$ lead to variations in this forcing from -1.67 to $-1.27 \mathrm{~W} \mathrm{~m}^{-2}$. Applying a better representation of natural particle emissions together with the modelgenerated aqueous sulfate production rate, we refine our previous estimate of the first indirect forcing by anthropogenic sulfate to be of the order $-0.30 \mathrm{~W} \mathrm{~m}^{-2}$. While the pattern of forcing from anthropogenic carbonaceous aerosols is approximately equal in each hemisphere $(-1.64$ versus $-1.38 \mathrm{~W} \mathrm{~m}^{-2}$ in the northern and southern hemispheres, respectively), that from anthropogenic sulfate remains primarily in the northern hemisphere. In addition, the first indirect forcing by anthropogenic sulfate varies from -0.31 to $-0.26 \mathrm{~W} \mathrm{~m}^{-2}$ when variations of up to a factor of 5 in the natural organic aerosol emissions are considered. Our estimated first indirect forcing by anthropogenic aerosols is $-1.85 \mathrm{~W} \mathrm{~m}^{-2}$, higher than the estimate of total indirect forcing, -1.1 to $-1.5 \mathrm{~W} \mathrm{~m}^{-2}$, by Lohmann et al. [2000]. In addition to the differences associated with model frameworks and emissions, our simplified cloud drop parameterization may be higher because we do not calculate the changes in droplet concentrations resulting from collision and coalescence. However, such calculations are highly uncertain when applied on the GCM grid scale.

[46] Sensitivity studies have been performed to quantify the uncertainty attributed to various chemical and physical properties of aerosols. The absorption of radiation by black carbon in clouds and its impact on the first indirect forcing has been examined. We find that if the effect of $\mathrm{BC}$ absorption in clouds is not included, the first indirect forcing by anthropogenic carbonaceous aerosols may be overestimated by $15-25 \%$ in regions where $\mathrm{BC}$ emissions are pronounced. Our sensitivity studies also reveal that the simulated forcing is highly sensitive to the existing level of natural aerosol abundance. Without accounting for the existing dust and sea-salt particles, the first indirect forcing by anthropogenic aerosols could be overestimated by at least a factor of 2. Moreover, if approximately half of dust emissions are due to anthropogenic activity [Tegen and Fung, 1995], then these might be responsible for an additional forcing of order $-1 \mathrm{~W} \mathrm{~m}^{-2}$. Therefore, further understanding of the interactions between anthropogenic components and natural particles together with a more thorough investigation of aerosol/cloud interactions is needed in order to quantify the first aerosol indirect effect on the radiation budget.

[47] Acknowledgments. This work was performed under the auspices of the U.S. Department of Energy by the University of California, Lawrence Livermore National Laboratory under contract W-7405-Eng-48. We are grateful for the partial funding of this work by NASA under the Global Aerosol Climatology Project, by NOAA under the Global Changes Program, and by DOE under the Atmospheric Radiation Measurement Program.

\section{References}

Ackerman, A. S., O. B. Toon, D. E. Stevens, A. J. Heymsfield, V. Ramanathan, and E. J. Welton, Reduction of tropical cloudiness by soot, Science, 288, 1042-1047, 2000. 
Andreae, M. O., Climatic effects of changing atmospheric aerosol levels, in World Survey of Climatology, vol. 16, Future Climates of the World, edited by A. Henderson-Sellers, pp. 341-392, Elsevier Sci., New York, 1995

Andreae, M. O., and H. Raemdonck, Dimethylsulfide in the surface ocean and the marine atmosphere: A global view, Science, 221 744-747, 1983.

Arimoto, R., R. A. Duce, B. J. Ray, W. G. Ellis Jr., J. D. Cullen, and J. T. Merrill, Trace elements in the atmosphere over the North Atlantic, J. Geophys. Res., 100, 1199-1214, 1995.

Bates, T. S., J. D. Cline, R. H. Gammon, and S. R. Kelly-Hansen, Regional and seasonal variations in the flux of oceanic dimethylsulfide to the atmosphere, J. Geophys. Res., 92, 2930-2938, 1987.

Benkovitz, C. M., Compilation of an inventory of anthropogenic emissions in the United States and Canada, Atmos. Environ., 16, 1551-1563, 1982.

Benkovitz, C. M., M. T. Scholtz, J. Pacyna, L. Tarrasón, J. Dignon, E. C. Voldner, P. A. Spiro, J. A. Logan, and T. E. Graedel, Global gridded inventories of anthropogenic emissions of sulfur and nitrogen, J. Geophys. Res., 101, 29,239-29,253, 1996.

Bohren, C. F., and D. R. Huffman, Absorption and Scattering of Light by Small Particles, 530 pp., John Wiley, New York, 1983.

Boucher, O., and U. Lohmann, The sulfate-CCN-cloud albedo effect: A sensitivity study with two general circulation models, Tellus, Ser. B, 47, 281-300, 1995

Charlock, T. P., and V. Ramanathan, The albedo field and cloud radiative forcing produced by a general circulation model with internally generated cloud optics, J. Atmos. Sci., 42, 1408-1429, 1985.

Chuang, C. C., and J. E. Penner, Effects of anthropogenic sulfate on cloud drop nucleation and optical properties, Tellus, Ser. B, 47, 566-577, 1995.

Chuang, C. C., J. E. Penner, and L. L. Edwards, Nucleation scavenging of smoke particles and simulated drop size distributions over large biomass fires, J. Atmos. Sci., 49, 1264-1275, 1992.

Chuang, C. C., J. E. Penner, K. E. Taylor, A. S. Grossman, and J. J. Walton, An assessment of the radiative effects of anthropogenic sulfate, J. Geophys. Res., 102, 3761-3778, 1997.

Chylek, P., and G. Videen, Scattering by a composite sphere and effective medium approximations, Opt. Commun., 146, 15-20, 1998.

Chylek, P., V. Srivastava, R. G. Pinnick, and R. T. Wang, Scattering of electromagnetic waves by composite spherical particles: Experiment and effective medium approximations, Appl. Opt., 27, 2396-2404, 1988.

Chylek, P., G. B. Lesins, G. Videen, J. G. D. Wong, R. G. Pinnick, D. Ngo, and J. D. Klett, Black carbon and absorption of solar radiation by clouds, J. Geophys. Res., 101, 23,365-23,371, 1996.

Cooke, W. F., C. Liousse, H. Cachier, and J. Feichter, Construction of a 1 degrees $\times 1$ degrees fossil fuel emission data set for carbonaceous aerosol and implementation and radiative impact in the ECHAM4 model, J. Geophys. Res., 104, 22,137-22,162, 1999

Duce, R. A., Sources, distribution, and fluxes of mineral aerosols and their relationship to climate, in Aerosol Forcing of Climate, edited by R. J. Charlson and J. Heinzenberg, pp. 43-72, John Wiley, New York, 1995.

Erickson, D. J., III, S. J. Ghan, and J. E. Penner, Global ocean-to-atmosphere dimethylsulfide flux, J. Geophys. Res., 95, 7543-7552, 1991.

Feichter, J., U. Lohmann, and I. Schult, The atmospheric sulfur cycle and its impact on the shortwave radiation, Clim. Dyn., 13, 235-246, 1997.

Feingold, G., R. Boers, B. Stevens, and W. R. Cotton, A modeling study of the effect of drizzle on cloud optical depth and susceptibility, J. Geophys. Res., 102, 13,527-13,534, 1997.

Ghan, S. J., C. C. Chuang, and J. E. Penner, A parameterization of cloud droplet nucleation, part I, Single aerosol type, Atmos. Res., 30, 197-221, 1993.

Ghan, S. J., L. R. Leung, R. C. Easter, and H. Abdul-Razzak, Prediction of cloud droplet number in a general circulation model, J. Geophys. Res. 102, 21,777-21,794, 1997.

Goudie, A. S., Dust storms in space and time, Prog. Phys. Geogr., 7, $502-$ 530, 1983.

Grant, K. E., C. C. Chuang, A. S. Grossman, and J. E. Penner, Modeling the spectral optical properties of ammonium sulfate and biomass burning aerosols: Parameterization of relative humidity effects and model results, Atmos. Environ., 33, 2603-2620, 1999.

Griffin, R. J., D. R. Cocker III, J. H. Seinfeld, and D. Dabdub, Estimate of global atmospheric organic aerosols from oxidation of biogenic hydrocarbons, Geophys. Res. Lett., 26, 2721-2724, 1999.

Guenther, A., et al., A global model of natural volatile organic compound emissions, J. Geophys. Res., 100, 8873-8892, 1995.

Hoffmann, T., J. R. Odum, F. Bowman, D. Collins, D. Klockow, R. C. Flagan, and J. H. Seinfeld, Formation of organic aerosols from the oxidation of biogenic hydrocarbons, J. Atmos. Chem., 26, 189-222, 1997.

Hoppel, W. A., J. W. Fitzgerald, G. M. Frick, R. E. Larson, and E. J. Mack, Aerosol size distributions and optical properties found in the marine boundary layer over the Atlantic ocean, J. Geophys. Res., 95, 36593686, 1990.

Intergovernmental Panel on Climate Change (IPCC), Climate Change 1995, The Science of Climate Change, edited by J. T. Houghton et al., 572 pp., Cambridge Univ. Press, New York, 1996.

Jones, A., and A. Slingo, Predicting cloud-droplet effective radius and indirect sulphate aerosol forcing using a general circulation model, Q. J. R. Meteorol. Soc., 122, 1573-1595, 1996.

Jones, A., D. L. Roberts, and A. Slingo, A climate model study of indirect radiative forcing by anthropogenic sulphate aerosols, Nature, 370, 450453, 1994

Kaufman, Y. J., and T. Nakajima, Effect of amazon smoke on cloud microphysics and albedo-Analysis from satellite imagery, J. Appl. Meteorol., 32, 729-744, 1993

Kawamoto, K., T. Nakajima, and T. Y. Nakajima, A global determination of cloud microphysics with AVHRR remote sensing, J. Clim., 14, 20542068, 2001.

Kettle, A. J., and M. O. Andreae, Flux of dimethylsulfide from the oceans: A comparison of updated data sets and flux models, J. Geophys. Res., $105,26,793-26,808,2000$

Kettle, A. J., et al., A global database of sea surface dimethylsulfide (DMS) measurements and a procedure to predict sea surface DMS as a function of latitude, longitude and month, Global Biogeochem. Cycles, 13, 399444, 1999.

Kiehl, J. T., R. J. Wolski, B. P. Briegleb, and V. Ramanathan, Documentation of Radiation and cloud routines in the NCAR community climate model (CCM1), NCAR Tech. Note, NCAR/TN $288+I A$, Natl. Cent. for Atmos. Res., Boulder, Colo., 1987.

Lacis, A. A., and J. E. Hansen, A parameterization for the absorption of solar radiation in the earth's atmosphere, J. Atmos. Sci., 31, 118-133, 1974

Liousse, C., J. E. Penner, C. C. Chuang, J. J. Walton, H. Eddleman, and H. Cachier, A global three-dimensional model study of carbonaceous aerosols, J. Geophys Res., 101, 19,411-19,432, 1996.

Liss, P. S., and L. Merlivat, Air-sea gas exchange rates: Introduction and synthesis, in The Role of Air-Sea Exchange in Geochemical Cycling, edited by P. Buat Menard, pp. 113-127, D. Reidel, Norwell, Mass., 1986.

Lohmann, U., and J. Feichter, Impact of sulfate aerosols on albedo and lifetime of clouds: A sensitivity study with the ECHAM4 GCM, J. Geophys. Res., 102, 13,685-13,700, 1997.

Lohmann, U., J. Feichter, C. C. Chuang, and J. E. Penner, Predicting the number of cloud droplets in the ECHAM GCM, J. Geophys. Res., 104, 9169-9198, 1999

Lohmann, U., J. Feichter, J. Penner, and R. Leaitch, Indirect effect of sulfate and carbonaceous aerosols: A mechanistic treatment, J. Geophys. Res., $105,12,193-12,206,2000$

Matthews, E., Global vegetation and land use: New high-resolution data bases for climate studies, J. Clim. Appl. Meteorol., 22, 474-487, 1983.

Mayol-Bracero, O. L., R. Gabriel, M. O. Andreae, T. W. Kirchstetter, T. Novakov, J. A. Ogren, P. J. Sheridan, and D. Streets, Carbonaceous aerosols over the Indian Ocean during INDOEX: Chemical characterization, optical properties and probable sources, J. Geophys. Res., 107, doi:10.1029/2000JD000039, in press, 2002

Monahan, E. C., D. E. Spiel, and K. L. Davidson, A model of marine aerosol generation via whitecaps and wave disruption, in Oceanic Whitecaps, edited by E. C. Monahan and G. MacNiocaill, pp. 167-174, D. Reidel, Norwell, Mass., 1986.

Penner, J. E., Carbonaceous aerosols influencing atmospheric radiation: Black and organic carbon, in Aerosol Forcing of Climate, edited by R. J. Charlson and J. Heintzenberg, pp. 91-108, John Wiley, New York, 1995.

Penner, J. E., C. S. Atherton, J. Dignon, S. J. Ghan, J. J. Walton, and S. Hameed, Tropospheric nitrogen: A three-dimensional study of sources, distributions, and deposition, J. Geophys Res., 96, 959-990, 1991.

Penner, J. E., H. Eddleman, and T. Novakov, Towards the development of a global inventory of black carbon emissions, Atmos. Environ., Part A, 27, $1277-1295,1993$

Penner, J. E., C. S. Atherton, and T. E. Graedel, Global emissions and models of photochemically active compounds, in Global AtmosphericBiospheric Chemistry, edited by R. G. Prinn, pp. 223-247, Plenum, New York, 1994

Penner, J. E., C. C. Chuang, and C. Liousse, The contribution of carbonaceous aerosols to climate change, in Proceedings of the 14th International Conference on Nucleation and Atmospheric Aerosols, edited by M. Kulmala and P. E. Wagner, pp. 759-769, Elsevier Sci., New York, 1996.

Penner, J. E., C. C. Chuang, and K. E. Grant, Climate forcing by carbonaceous and sulfate aerosols, Clim. Dyn., 14, 839-851, 1998.

Penner, J. E., C. Chuang, and K. Grant, Climate change and radiative forcing by anthropogenic aerosols: Research findings during the last 5 years, submitted to La Jolla Int. Sch. of Sci., The Inst. for Adv. Phys. Stud., La Jolla, Calif, 1999. 
Platnick, S., and S. Twomey, Determining the susceptibility of cloud albedo to changes in droplet concentration with the advanced very high resolution radiometer, J. Appl. Meteorol., 33, 334-347, 1994.

Prospero, J. M., Long term measurements of the transport of African mineral dust to the Southeastern United States: Implications for regional air quality, J. Geophys. Res., 104, 15,917-15,927, 1999.

Prospero, J. M., M. Uematsu, and D. L. Savoie, Mineral aerosol transport to the Pacific Ocean, in Chemical Oceanography, vol. 10, edited by J. P. Riley, R. Chester, and R. A. Duce, pp. 188-218, Academic, San Diego, Calif., 1989.

Pruppacher, H. R., and J. D. Klett, Microphysics of Clouds and Precipitation, 714 pp., D. Reidel, Norwell, Mass., 1978

Rau, G. H., J. E. Penner, H. E. Eddleman, J. K. Hobson, and J. J. Walton, A model dust/micronutrient delivery to the ocean, Trans. $A G U, 75(44), 377$, 1994.

Rotstayn, L. D., Indirect forcing by anthropogenic aerosols: A global climate model calculation of effective-radius and cloud-lifetime effects, J. Geophys. Res., 104, 9369-9380, 1999.

Rotstayn, L. D., and J. E. Penner, Indirect aerosol forcing, quasi forcing, and climate response, J. Clim., 14, 2960-2975, 2001.

Savoie, D. L., J. M. Prospero, and E. S. Saltzman, Nitrate, nonseasalt sulfate and methanesulfonate over the Pacific Ocean, in Chemical Oceanography, vol. 10, edited by J. P. Riley, R. Chester, and R. A. Duce, pp. 219-250, Academic, San Diego, Calif., 1989.

Savoie, D. L., J. M. Prospero, R. J. Larsen, F. Huang, M. Izaguirre, T. Huang, and T. H. Snowdon, Nitrogen and sulfur species in Antarctic aerosols at Mawson, Palmer Station, and Marsh (King George Island), J. Atmos. Chem., 17, 95-122, 1993.

Spiro, P. A., D. J. Jacob, and J. A. Logan, Global inventory of sulfur emissions with $1^{\circ} \times 1^{\circ}$ resolution, J. Geophys. Res., 97, 6023-6036, 1992

Stephens, G. L., Optical properties of eight water cloud types, CSIRO Tech. Pap. 36, 35 pp., Aust. Div. Atmos. Phys., 1979.

Taylor, K. E., and S. J. Ghan, An analysis of cloud liquid water feedback and global climate sensitivity in a general circulation model, J. Clim., 9, 907-918, 1992

Tegen, I., and I. Fung, Modeling of mineral dust in the atmosphere: Source, transport, and optical thickness, J. Geophys. Res., 99, 22,897-22,914, 1994

Tegen, I., and I. Fung, Contribution to the atmospheric mineral aerosol load from land surface modification, J. Geophys. Res., 100, 18,707-18,726, 1995.

Tegen, I., A. A. Lacis, and I. Fung, The influence on climate forcing of mineral aerosols from disturbed soils, Nature, 380, 419-422, 1996.

Twomey, S. A., Atmospheric Aerosols, 302 pp., Elsevier Sci., New York, 1977a.

Twomey, S. A., The influence of pollution on the shortwave albedo of clouds, J. Atmos. Sci., 34, 1149-1150, 1977b.

Twomey, S. A., Aerosols, clouds and radiation, Atmos. Environ., Part A, 25, 2435-2442, 1991

Walton, J. J., M. C. MacCracken, and S. J. Ghan, A global-scale Lagrangian trace species model of transport, transformation, and removal process, J. Geophys. Res., 93, 8339-8354, 1988.

Wanninkhof, R., Relationship between wind speed and gas exchange over the ocean, J. Geophys. Res., 97, 7373-7382, 1992.

Webb, R. S., C. E. Rosenweig, and E. R. Levine, Specifying land surface characteristics in general circulation models: Soil profile data set and derived water-holding capacities, Global Biogeochem. Cycles, 7, 97108,1993

Williamson, D. L., J. T. Kiehl, V. Ramanathan, R. E. Dickinson, and J. J. Hack, Description of NCAR community climate model (CCM1), NCAR Tech. Note, NCAR/TN 285+STR, 112 pp., Natl. Cent. for Atmos. Res. Boulder, Colo., 1987.

Zobler, L., A world soil file for global climate modeling, NASA Tech. Memo. 87802, 1986.

C. C. Chuang and K. E. Grant, Atmospheric Science Division, Lawrence Livermore National Laboratory, Livermore, CA 94550, USA. (chuang@ llnl.gov)

K. Kawamoto, Atmospheric Sciences Division, NASA Langley Research Center, Hampton, VA 23681, USA.

J. E. Penner, Department of Atmospheric, Oceanic, and Space Sciences, University of Michigan, Ann Arbor, MI 48109, USA.

J. M. Prospero, Cooperative Institute for Marine and Atmospheric Studies, University of Miami, Miami, FL 33149, USA.

G. H. Rau, Institute of Marine Sciences, University of California, Santa Cruz, CA 95064, USA. 